\title{
La dialéctica Estado nacional vs. revitalización indianista en Bolivia ${ }^{1}$
}

\section{The Nation State v. Indianist Revitalization Dialectic in Bolivia}

\author{
Juan J. R. Villarías-Robles \\ Grupo de Investigación "Antropología Comparada \\ de España y América" (ACEA) \\ Centro de Ciencias Humanas y Sociales. CSIC. Madrid
}

\section{RESUMEN}

Desde comienzos de 2006, la república de Bolivia cuenta con el primer presidente indígena de su historia: el aymara Evo Morales, dirigente sindical y cabeza de lista del llamado "Movimiento al Socialismo" (MAS). Su ascensión política, victoria electoral y programa de gobierno han llamado mucho la atención de los medios informativos internacionales y han sido objeto de valiosos análisis políticos y sociológicos. Desde la perspectiva de una antropología comparada, el proceso se ajusta bien, en el contexto cultural andino, a lo que Anthony Wallace llamara un "movimiento de revitalización", desencadenado por la convergencia, en un periodo de crisis iniciado en 1997, de varias condiciones estructurales de duración histórica variable en Bolivia como proyecto nacional.

\footnotetext{
${ }^{1}$ Una primera versión de este ensayo fue leída ante los asistentes al XXVII Curso "Julio Caro Baroja" de Etnología Española del CSIC, dando lugar a un coloquio que sólo podía contribuir a enriquecer el texto en una versión más acabada. Deseo destacar especialmente los comentarios críticos de Fermín del Pino y Pedro Tomé. Mi planteamiento estuvo animado en buena medida por el diferente que había expuesto meses antes Josep M. Barnadas, en una conferencia pronunciada en el Departamento de Antropología de España y América del CSIC (Barnadas 2006) acerca del significado histórico de la victoria de Evo Morales y de su partido, "Movimiento al Socialismo" (MAS), en las elecciones generales de diciembre de 2005. Tras el Curso "Julio Caro Baroja", el texto se vería enriquecido por las conversaciones mantenidas con Beatriz Vitar sobre el fenómeno de la revitalización en la actualidad de Bolivia, España, Chile, Argentina y otros países, en América y fuera de América. Deseo expresar mi agradecimiento adicional a mis amigos y colegas en Bolivia — Itala de Mamán, David Pereira, Susy Portillo, el propio Josep M. Barnadas- por su información verbal y epistolar, y su perspectiva, sobre lo acontecido en el querido país desde 1998, el último año en que allá estuve. La responsabilidad de lo expuesto, sin embargo, sólo puede ser mía.
} 
Palabras clave: Bolivia, Evo Morales, Movimiento de Revitalización, Duración histórica, Estado nacional.

\section{SUMMARY}

Since early in 2006, the republic of Bolivia has been ruled by the first indigenous president in that country's history: the Aymara Evo Morales, union leader and first name in the ballot of the so-called "Movement for Socialism" (MAS). His political rise, electoral victory and government program have drawn considerable attention from international mass media and been the subject of valuable political and sociological analyses. From the perspective of comparative anthropology, the process can be understood as an instance, in the Andean cultural context, of what Anthony Wallace called a "revitalization movement," triggered by the convergence, at a juncture of crisis begun in 1997, of a number of historical conditions of variable duration in Bolivia as a national project.

Key Words: Bolivia, Evo Morales, Revitalization Movement, Historical Duration, National State.

Escribo estas líneas tras la nueva victoria del dirigente aymara Juan Evo Morales Aima y su partido, "Movimiento al Socialismo" (MAS), en las elecciones generales celebradas en Bolivia en diciembre de 2009. El también líder sindical ha ganado la reelección a la presidencia de la República con el $64,22 \%$ de los votos y obtenido para el MAS la mayoría de diputados y senadores que necesitaba en la "Asamblea plurinacional" contemplada en la nueva Constitución para poner por obra lo en ella previsto. Según reza el preámbulo de este importante documento, promulgado en febrero, Bolivia queda refundada como:

Estado Unitario Social de Derecho Plurinacional Comunitario [sic], que integra y articula los propósitos de avanzar hacia una Bolivia democrática, productiva, portadora e inspiradora de la paz, comprometida con el desarrollo integral y con la libre determinación de los pueblos (Asamblea Constituyente de Bolivia 2008: 2).

Esta nueva Bolivia sustituye al "Estado colonial, republicano y neoliberal" vigente hasta la fecha e integra a "las naciones y pueblos indígena-originario-campesinos" que ya existían en tiempos prehispánicos, a los que "se garantiza su libre determinación en el marco de la unidad del Estado, que consiste en su derecho a la autonomía, al autogobierno, a su cultura, al reconocimiento de sus instituciones y a la consolidación de sus entidades territoriales" (artículo 2).

Durante la precampaña electoral, Morales había reiterado públicamente su convencimiento de que, después de "quinientos años de opresión", a estas naciones y pueblos corresponde el derecho de ejercer el gobierno por otro 
tanto, uniéndose a ellos los demás actores excluidos en el país, "en busca de igualdad" (Los Tiempos, Cochabamba, 20 de septiembre de 2009) (véase Mapa 1). La nueva Constitución alude expresamente a "las comunidades interculturales y afrobolivianas". Junto a estas comunidades, esos "pueblos y naciones" conforman "la nación boliviana" (artículo 3). En consecuencia, son declarados "idiomas oficiales [...] el castellano y todos los idiomas de las naciones y pueblos indígena-originario-campesinos". Los cuales son treinta y seis, nombrados uno a uno; entre ellos, el aymara, el quechua, el uruchipaya y el guaraní (artículo 5.I).

A la rotunda victoria de Morales y el MAS no debía de ser ajena la situación de bonanza económica por la que atraviesa el país, no obstante la recesión en la mayor parte del mundo desde 2008: "crecimiento medio del $4,5 \%$ anual [desde 2006], inflación bajo control, tipo de cambio estable, reservas multimillonarias, superávit fiscal y aumento del comercio, explica Gonzalo Chávez, director de la Escuela de Producción y Competitividad de la Universidad Católica de Bolivia" (El País, Madrid, 5 de diciembre de 2009).

Esta buena situación -derivada en buena parte de la nacionalización de los yacimientos de gas y petróleo y de las regalías impuestas a las compañías productoras - contrasta notablemente con la anterior a 2006. En febrero de 2003, por ejemplo, la balanza por cuenta corriente acumulaba un saldo deudor y el déficit público ascendía al 8,6\% del PIB. A instancias del Fondo Monetario Internacional, el entonces Gobierno del liberal Gonzalo Sánchez de Lozada inició la aplicación de un plan de austeridad para reducirlo al 5,5\% en el plazo de un año. Pero el primer efecto fue un motín de la policía que causaría treinta y tres muertos y cerca de doscientos heridos, y el Gobierno acabaría abandonando el proyecto (Ediciones Akal 2003: 410412; Sivak 2008: 151-152).

\section{LA ASCENSIÓN DE EVO MORALES Y EL MAS (1995-2005)}

Desde la sociología y la ciencia política se ha llamado la atención sobre un contexto internacional de creciente importancia de los partidos, organizaciones y movimientos indígenas en el conjunto de América Latina desde la década de 1980; contexto que habría favorecido el singular ascenso de Morales y el MAS. Para el caso concreto de Bolivia, se han resaltado factores adicionales, convergentes con el económico: como el impacto de las reformas institucionales del Gobierno de coalición entre el Movimiento Nacionalista Revolucionario (MNR), el Movimiento Bolivia Libre (MBL) y el Movimiento Revolucionario Tupaq Katari de Liberación (MRTKL), entre 1993 y 1997 (Van Cott 2003: 40-49); así como el agotamiento ulterior de la es- 


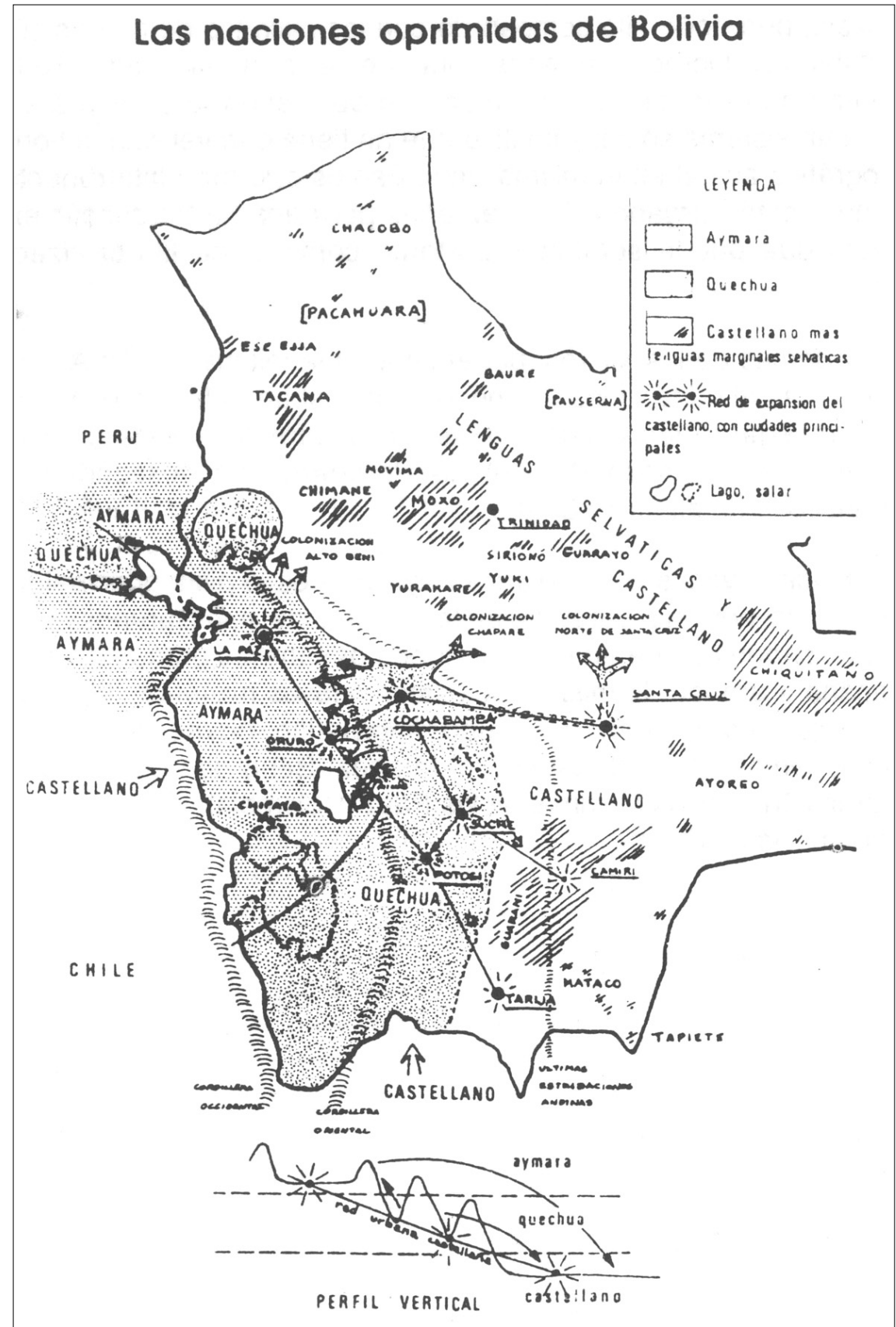

MAPA 1: Fuente: Albó y Barnadas 1990: 16. 
tructura de partidos y gobernabilidad surgida tras la caída de la última dictadura, en 1982, en un país con una numerosa población indígena pobre y excluida (Barreda 2006; Lazarte 2006); el neoliberalismo instalado en el país desde 1985, que habría transformado el viejo antagonismo social y político de sindicatos y partidos de izquierda en otro nuevo de indígenas, marginados y dependientes de la economía informal (Iglesias Turrión 2007: 261, 267272); la estrecha relación de origen del MAS, y su alianza posterior, con movimientos u organizaciones no indígenas, acorde con un discurso político incluyente, que posibilitaría la ocupación del espacio tradicional de la izquierda y del populismo en el país (Alcántara y Marenghi 2007: 71-99); y, finalmente, el carácter fluido y ambiguo del sentido de pertenencia étnica en la población, haciendo difícil en Bolivia la polarización bajo este criterio $\mathrm{y}$, en consecuencia, fácil para un partido decidido como el MAS el atraer tanto a votantes originarios como a los de ascendencia europea o africana (Madrid 2008: 477).

En 1993, en efecto, el liberal Sánchez de Lozada, del MNR, formó un Gobierno de coalición con el izquierdista MBL, de Antonio Araníbar, y el indígena MRTKL, del pedagogo aymara Víctor Hugo Cárdenas. El apelativo "Tupaq Katari" en las siglas de este último era un homenaje al gran jefe aymara de la sublevación andina de 1780-1781 contra los españoles, a quienes llegó a asediar por dos veces en La Paz. Este Gobierno de coalición de 1993 era típico del régimen de "democracia pactada" entre partidos que surgiera en 1982 y que haría de Bolivia uno de los países constitucionalmente más estables del Continente por espacio de más de veinte años (Barreda 2006: 67-71). Pero en buena medida por la presencia en él del MRTKL —ocupando Cárdenas la vicepresidencia de la República-, el Gobierno adoptó como novedad, bajo el lema "Plan de todos", varias medidas sin precedentes que tendrían consecuencias significativas a largo plazo en el país: una reforma educativa para posibilitar la enseñanza pública en las lenguas indígenas, una campaña de inscripción en el censo de electores del campo, y cambios significativos en la Constitución y en el régimen electoral. La reforma en la Constitución redefiniría a Bolivia como una "República unitaria, multiétnica y pluricultural”. El nuevo régimen electoral introduciría circunscripciones uninominales y plurinominales para el Congreso con el fin de incentivar los acuerdos de partidos desde la base, a través de candidaturas locales y provinciales. Una "Ley de Participación Popular", además, crearía centenares de circunscripciones municipales nuevas en el campo y reforzaría la autonomía de los municipios frente a las instancias administrativas superiores (las provincias y los departamentos).

En 1995, para concurrir a las primeras elecciones municipales al amparo de esta ley, sindicalistas aymaras y, sobre todo, quechuas, afiliados a la 
confederación sindical mayoritaria en el campo, la CSUTCB ("Confederación Sindical Unitaria de Trabajadores Campesinos de Bolivia"), así como indígenas de la organización mayoritaria en las tierras bajas, la CIDOB ("Confederación Indígena del Oriente Boliviano"), y miembros de otras plataformas, constituyeron la "Asamblea por la Soberanía de los Pueblos" (ASP). Entre los fundadores destacaron el quechua Alejo Véliz - agricultor y natural de la provincia de Cercado (en el departamento de Cochabamba) - y el aymara Evo Morales, natural del departamento de Oruro, en la alta Bolivia, en el occidente, pero afincado en la provincia del Chapare (en el departamento de Cochabamba) y ya bien conocido entre los cultivadores de coca, o "cocaleros", en esa zona subtropical del país. La mayoría de estos cultivadores, como Morales y su familia, eran inmigrantes procedentes de la parte alta de Bolivia, la que más había sufrido la política neoliberal de desmantelamiento de la minería estatal del estaño a partir de 1985. Otras familias afectadas optaron por emigrar a la periferia de las ciudades, para intentar vivir allí de una creciente economía informal. La ciudad de El Alto —en origen un suburbio de La Paz, junto al aeropuerto- tendría principalmente este nacimiento.

La ASP obtuvo en esas elecciones de 1995, bajo la denominación registrada "Izquierda Unida", el 11,1\% de los votos válidos en el departamento de Cochabamba, el mejor resultado de estas siglas por departamentos ${ }^{2}$. En las generales de 1997, Morales, bajo las mismas siglas, llegó a ser elegido diputado al Congreso por su circunscripción, con un porcentaje de votos superior al conseguido por cualquier otro candidato en las elecciones.

No mucho después, el sindicalista abandonaría la ASP para fundar con otros cocaleros el "Instrumento Para la Soberanía de los Pueblos" (IPSP) y en 1999 se acogió a las siglas registradas "MAS" ("Movimiento al Socialismo") para concurrir a las elecciones municipales de ese año. El nuevo partido obtuvo el 3,268\% de los sufragios válidos en toda Bolivia.

Pero el ascenso más espectacular se produjo menos de tres años después, en las generales de junio de 2002, cuando el IPSP-MAS resultó el segundo partido más votado con un porcentaje cercano al $21 \%$, a menos de tres puntos de distancia del vencedor, el MNR del ex-presidente Sánchez de Lozada, desvinculado ya de sus antiguos socios MRTKL y MBL, que no concurrían. Junto con el IPSP-MAS irrumpió en el Congreso otra nueva fuerza política, el "Movimiento Indígena Pachakuti" (MIP), del sindicalista y exguerrillero aymara Felipe Quispe, que consiguió el 6,09\% de los votos.

De la estructura de partidos surgida en Bolivia en 1982, lo más pareci-

\footnotetext{
${ }^{2}$ He tomado estos y los demás datos electorales mencionados en este ensayo de los oficiales publicados por la Corte Nacional Electoral de Bolivia, disponibles en http:// www.cne.org.bo.
} 
do que quedaba de un partido de izquierda — en el sentido europeo de la palabra - era el "Movimiento de Izquierda Revolucionaria" (MIR) del expresidente Jaime Paz Zamora, de la Internacional Socialista. Obtuvo el 16,32\% de los sufragios. El partido populista "Conciencia de Patria" (CONDEPA), del periodista de radio y televisión Carlos Palenque, había desaparecido. La también populista "Unidad Cívica Solidaridad" (UCS), del empresario cervecero Max Fernández, cosechó un mero 5,51\%. El espacio electoral de ambas fuerzas - una tercera parte de la participación en las elecciones generales anteriores - lo ocupaba ahora, pero sólo en parte, la también recién creada "Nueva Fuerza Republicana" (NFR) del ex-militar y antiguo socio de MBL Manfred Reyes Villa, apoyado por el quechua Alejo Véliz, con un 20,91\%.

Unas semanas después de las elecciones, Sánchez de Lozada y Paz Zamora, otrora adversarios acérrimos, suscribieron el inesperado "Plan Bolivia de Responsabilidad Nacional", con el que pretendían sacar al país de la crisis económica a través del desarrollo de la industria del gas natural. A cambio de ser votado para Presidente, Sánchez de Lozada se comprometió con Paz Zamora a ceder al MIR seis de las dieciséis carteras ministeriales y cinco embajadas importantes (entre ellas, las de Francia y España), así como la administración de varios departamentos.

En agosto, un Congreso Nacional plurilingüe, que requirió de intérpretes para traducir las palabras de unos treinta diputados indígenas, eligió a Sánchez de Lozada nuevo presidente de la República; pero con los votos no sólo del MIR sino también de la populista UCS y hasta de la conservadora ADN, que fundara el ex-dictador Hugo Bánzer. El periodista e historiador independiente - aunque cercano al MNR - Carlos Mesa Gisbert fue elegido Vicepresidente. Evo Morales fue el segundo candidato más votado, contando con el respaldo del MAS y del MIP. Un año después — julio de 2003-, la NFR se sumó al Gobierno de coalición MNR-MIR presidido por Sánchez de Lozada, terminando así de cerrar el frente contra el MAS y el MIP.

Abandonado en febrero de 2003 el plan de austeridad alentado por el Fondo Monetario Internacional, la opción alternativa de sacar el país de la crisis mediante el impulso a la industria de extracción y exportación de gas natural suscitó mayores protestas aún, protagonizadas principalmente por comunidades rurales y sectores medios urbanos, en el oeste y centro del país. Lo que se ponía en entredicho no era tanto el desarrollo de esta industria cuanto el dejarla en manos de grandes empresas transnacionales y que el gas se exportara a México y los EE. UU. a través de Chile, país con el que Bolivia mantiene un contencioso territorial desde 1883. El 17 de octubre, tras un mes de violentos enfrentamientos, sobre todo en la ciudad de El Alto y en La Paz — saldados con más de setenta muertos y centenares de heridos a causa de la acción de la policía y el ejército-, Sánchez de 
Lozada renunció a la Presidencia y abandonó el país. El vicepresidente Mesa Gisbert lo sustituyó en el cargo, formando nuevo Gobierno con independientes de los partidos. El hecho significaba el fin del régimen de gobernabilidad surgido en 1982.

Mesa Gisbert, no obstante, renunciaría también él a la Presidencia menos de dos años más tarde, víctima del fuego cruzado entre dos movilizaciones contrapuestas: la que abogaba por la nacionalización de los recursos naturales de Bolivia - y una nueva constitución que la asegurara-, protagonizada principalmente por el MAS, y una mayoría hostil a tal iniciativa en el Congreso Nacional, nacida de las elecciones de 2002, que proponía la autonomía de los departamentos como salvaguarda frente a un Ejecutivo nacionalizador y redistribuidor.

En las elecciones generales anticipadas de diciembre de 2005, con una participación del 84,51\%, el MAS resultó el vencedor, por mayoría absoluta (el 53,74\% de los sufragios válidos), lo que hacía casi automática la elección de Morales en el Congreso como nuevo Presidente. La coalición conservadora "Poder Democrático y Social" (PODEMOS), del ex-presidente Jorge "Tuto" Quiroga, sucesor de Bánzer, quedó muy atrás, con un 28,59\%. El MIR había dejado de existir. Una facción del mismo, bajo las siglas "Frente de Unidad Nacional" (UN), obtuvo sólo el 7,8\%. El histórico MNR —el que fuera partido guía de la "Revolución Nacional" de 1952, y liberal tras la restauración de la democracia- apenas cosechó el 6\%. La populista NFR de Reyes Villa, menos del 1\%. El MAS atrajo esta vez incluso a la mayor parte del voto indígena del MIP, que consiguió ahora no más que el 2,16\%.

Pero el mismo día, por otro lado - en la elección a las prefecturas de los departamentos-, el MAS sólo pudo imponerse en las de Oruro, Potosí y Chuquisaca, en la alta Bolivia del oeste. En las tierras bajas del oriente y en el sur del país (Santa Cruz, Beni, Pando y Tarija), donde se concentran los yacimientos de gas natural y de petróleo, así como la población de ascendencia europea, las que vencieron fueron las candidaturas autonomistas. El antagonismo de base étnica en el Congreso pasaba entonces a expresarse también en el territorio de la República, y así ha permanecido hasta hoy, lastrando la presidencia de Morales. En 2001 ya había surgido en Santa Cruz un movimiento secesionista, el "Movimiento Nación Camba ${ }^{3}$ de Liberación (MNC-L)” (Rodríguez Mir 2008: 343). Los autonomistas, mayoritarios en estos departamentos, opondrían un "Estado unitario, nacional e intercultural, constitucional de derecho, democrático y social" al "Plurinacional Comunitario" del MAS (Los Tiempos, 19 de octubre de 2007).

\footnotetext{
3 "Camba" es el término (adjetivo y sustantivo) con el que se conoce coloquialmente en Bolivia al habitante de los departamentos del Oriente, especialmente el de Santa Cruz.
} 
BOLIVIA, ENERO DE 2006

Desde una perspectiva político-electoral, como la expuesta resumidamente hasta aquí, el éxito del MAS y de Morales representaría - mejor que ningún otro partido comparable en América Latina desde la década de 1980 en la oposición al neoliberalismo- la pujanza de lo que Raúl L. Madrid (2008) ha llamado "etnopopulismo": la movilización de sectores originarios, mestizos, y hasta de ascendencia europea, en ciudades y campos, en torno a programas en los que aparecen reivindicaciones de interés para la población indígena socialmente discriminada y políticamente excluida (derecho al uso de la lengua nativa, autogobierno en el territorio de origen, igualdad de acceso a las administraciones) en combinación con algunas de las características del populismo clásico en el subcontinente, entre la década de 1930 y la de 1960: un discurso incluyente interclasista, la crítica a los partidos tradicionales y el llamamiento a la nacionalización de los recursos naturales y la redistribución amplia de las rentas del Estado.

Madrid ha relativizado el efecto de las reformas institucionales adoptadas por el Gobierno MNR-MBL-MRTKL entre 1993 y 1997, argumentando que no podían determinar por sí mismas el comportamiento de la mayoría de los electores, menos aún fuera del departamento de Cochabamba. Como han señalado asimismo Alcántara y Marenghi (2007: 76-79, 86-90), corresponde por eso a Morales y al MAS, así como a las organizaciones de diverso tipo con éste asociadas, el principal mérito de haber sabido hilvanar un discurso étnica y socialmente plural junto a un programa que pudiera apoyar en las urnas la población indígena — residente mayoritariamente en el campoa la vez que las clases trabajadoras y medias de las ciudades. Un discurso y un programa exclusivamente etnocéntricos, como los del MIP de Quispe, o exclusivamente populistas, como los de NFR de Reyes Villa, no podían tener el mismo atractivo y por ello quedarían a la postre en minoría.

El "atractivo carismático" de Morales para quienes votaron por el MAS habría tenido también su importancia, pero no desmentiría el carácter populista apuntado (Madrid 2008: 491). Sin embargo, como ha reconocido este autor, a diferencia del populismo clásico el MAS contaba con una organización estable en su base (ibid:: 492), lo que le hacía menos vulnerable a los efectos del personalismo y las relaciones clientelares tejidas en torno al líder que sufrieran CONDEPA y UCS. Por otro lado, el MAS no sería propiamente "un partido político" cuanto "un conjunto de numerosos movimientos sociales" (ibid.: 493), como su mismo nombre ya sugiere. También peculiar es que su ascenso fuera tan rápido y vertiginoso, en comparación con lo sucedido a otros partidos semejantes en América Latina (ibid.: 503) y que este ascenso dependiera en sumo grado de la coyuntura sociopolítica y económica acaecida en torno al cambio de siglo (ibid.: 504-505). 
Un planteamiento diferente, aunque suplementario al de este análisis político-sociológico, tal vez permitiera entender mejor esas y otras peculiaridades. Es el que aquí se ofrece, desde la doble perspectiva de una antropología comparada - especialmente sobre el cambio cultural, y no sólo en América Latina- y una historia concebida no como sucesión de acontecimientos irrepetibles e impredecibles más allá del corto o medio plazo, sino como un proceso sistémico complejo en el que concurren realidades humanas de diferente ritmo de duración.

Desde esta diferente perspectiva, llama la atención en primer lugar lo acontecido el 21 de enero de 2006, tras la rotunda victoria de Morales en las elecciones anticipadas de diciembre de 2005. Ese día el vencedor fue investido nuevo presidente de Bolivia en las ruinas prehispánicas de Tiahuanaco (a unos 70 kms. al oeste de La Paz) en calidad de "Gran Mallku [jefe] de los pueblos originarios andinos". Presenciaron el acto unas setenta mil personas, quienes habían venido congregándose en el lugar desde días antes. Entre los asistentes había jefes indígenas no sólo de Bolivia, sino también de otros países de América (incluso de América del Norte), quienes aclamaron al dirigente cocalero al grito de "iQhallalla el nuevo Pachakuti!" (La Razón, La Paz, 22 de enero de 2006; Los Tiempos, misma fecha).

"Qhallalla" (también escrito "Jallalla") es una interjección aymara y quiere decir "¡Viva!" (Layme Pairumani et alii 1992: 115); "Pachakuti" es un sustantivo compuesto aymara y quechua y significa "dar media vuelta", así en el espacio como en el tiempo (Lara 1997: 109). A principios del siglo XVII, al menos los aymaras lo entendían como "el juyzio final" (Bertonio 1984: II, 242). El quechua y el aymara son los idiomas nativos más hablados en los Andes Centrales. A juicio del enciclopédico Antonio Tovar (1984: 49-50), los dos no serían lenguas de la misma familia; tal vez ni siquiera del mismo tronco, con independencia de los muchos préstamos tomados del uno por el otro.

En esa ceremonia del 21 de enero de 2006 se encontraban también dignatarios internacionales, como el presidente de Venezuela, Hugo Chávez, y el candidato indigenista a la presidencia del Perú, Ollanta Humala. España no destacó ninguna representación oficial. En el momento culminante del acto (véase Foto 1), un sacerdote aymara pasó a Morales (ataviado con un unku o manto rojo y tocado en la cabeza con un chuku o gorro en rojo y amarillo) un bastón de mando labrado en oro, plata y pedrería, símbolo de su nueva autoridad. La hermana mayor del ungido, Esther Morales Aima, fue designada "Primera Dama de Bolivia". Tras invocar al dios Sol (Inti) y a la Madre Tierra (Pachamama) — dos nombres aymaras y quechuas-, Morales pronunció un discurso en el que aseguró que empezaba "la nueva era, el nuevo milenio [...], el fin del neoliberalismo [...]”. Anunció la convo- 
catoria de una "Asamblea Constituyente" de Bolivia en la ciudad de Sucre para "refundar la República". "No queremos vengarnos de quienes nos han sojuzgado - aclaró-; lo que queremos es unidad e igualdad [...]. Queremos enseñar a gobernar con honestidad, con responsabilidad para cambiar la situación económica del pueblo boliviano [...]. Llegó la hora de cambiar esa mala historia de saqueo de nuestros recursos naturales, de discriminación, de humillación, de odio, de desprecio [...]. Nos hemos convencido que concentrar el capital en pocas manos no es [...] la solución para los pobres del mundo". Asimismo, expresó su deseo de unión de todos los pueblos originarios de América "para doblar la mano al Imperio" (en referencia a los EE. UU.) (La Razón, 22 de enero de 2006; Los Tiempos, misma fecha; Página 12, Buenos Aires, 30 de enero de 2006).

No era la primera vez que un indígena accedía a la presidencia de un país de América (ese honor le corresponde al zapoteca Benito Juárez en México); pero sí que se hiciera de ese modo: mediante un ritual ajeno a las tradiciones políticas de Occidente e invocando al pasado prehispánico del Nuevo Mundo; todo ello antes de la ceremonia de investidura en el Congreso Nacional. En julio de 2001 el peruano Alejandro Toledo había acudido al Cusco y las ruinas de Machu Picchu para un acto similar, pero después de ser investido presidente constitucional en Lima (El País, 30 de julio de 2001).

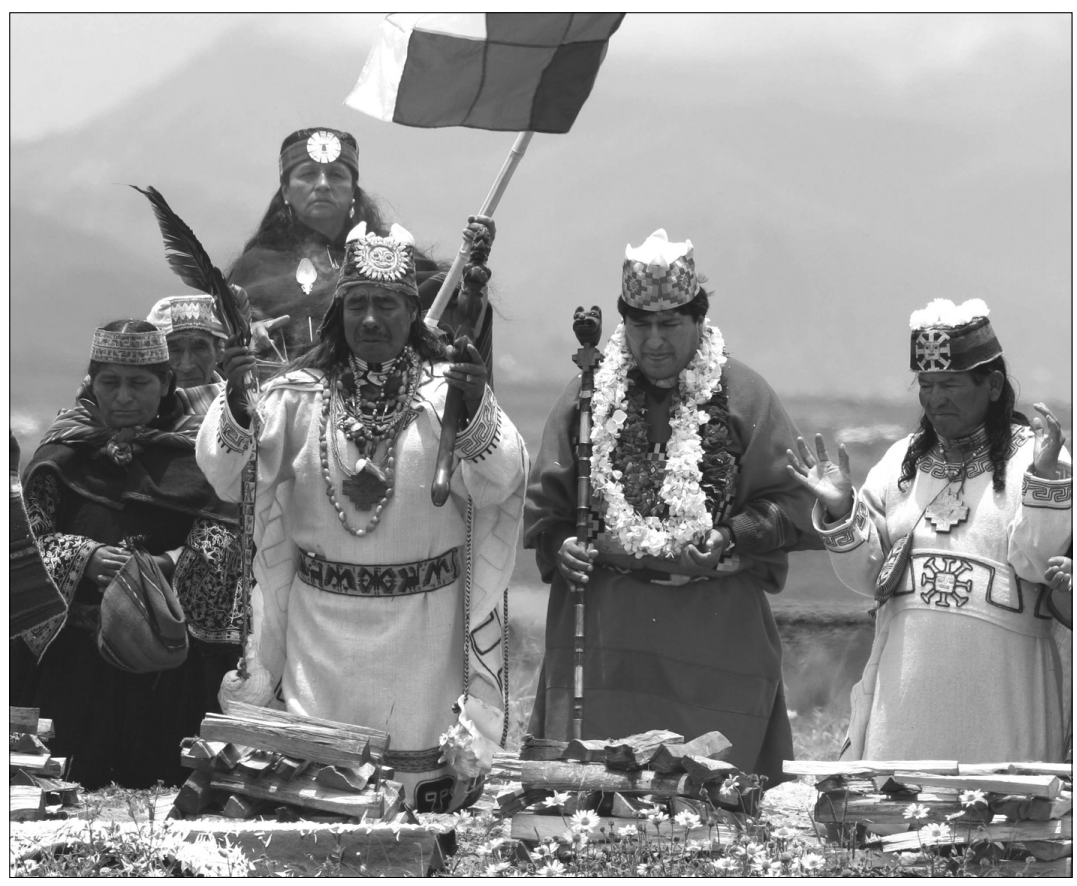

FOTO 1: C REUTERS. 
Morales fue investido nuevo Presidente de Bolivia según las formalidades republicanas el domingo 22 de enero de 2006, con posterioridad a la ceremonia en Tiahuanaco. En el Congreso Nacional, ante los representantes electos de la ciudadanía (diputados y senadores) y "presidentes de 11 países [entre ellos, Hugo Chávez, Alejandro Toledo, el argentino Néstor Kirschner y el chileno Ricardo Lagos], un Príncipe [don Felipe de Borbón], 3 expresidentes de Bolivia y personalidades invitadas", y tras el discurso de despedida del presidente saliente, Eduardo Rodríguez, Morales recibió el "Bastón de Mando de Capitán General de la Fuerzas Armadas" del almirante Marco Antonio Justiniano, "Comandante en Jefe de las Fuerzas Armadas" (Los Tiempos, 22 de enero de 2006) $)^{4}$.

Al día siguiente de esa investidura en el Congreso, el lunes 23 de enero, Morales formó el nuevo Gobierno del país con "ex dirigentes sindicales, analistas y activistas”. Entre ellos destacaba Álvaro García Linera, el nuevo vicepresidente de la República. García Linera era "docente y analista [...], un intelectual comprometido con posturas de izquierda e indígenas". "A los 13 años comencé leyendo a Engels y Kant. Y a los 15 ya había terminado los tres tomos de El Capital', declaró. A principios de la década de 1990, se había unido al Ejército Guerrillero Tupaq Katari, fundado por Felipe Quispe, por lo que pasaría cinco años en prisión (La Razón, 22 y 23 de enero de 2006).

Como ministro de Hidrocarburos, Morales nombró al periodista y abogado Andrés Soliz Rada. Procedente de la populista CONDEPA, Soliz había pasado a ser asesor del MAS en esta materia. Ese 23 de enero de 2006, poco después de jurar su cargo, anunció que "procedería inmediatamente a registrar [todas las reservas de gas] del país como propiedad boliviana en los listados existentes en registros y bolsas internacionales" (El País, ibid.).

En el nuevo Gobierno entraban cuatro mujeres; entre ellas, Alicia Muñoz como ministra de Gobernación. Era la primera mujer en la historia de Bolivia puesta al frente de la policía (La Razón, 24 de enero de 2006). En la legislatura anterior, había sido senadora, declarando en una de sus sesiones que "el pueblo cerrará el Parlamento si el Legislativo permanece ajeno a las demandas populares" (El País, ibid.).

El dirigente de la Federación de Juntas Vecinales de El Alto, Abel Mamani, era ahora ministro sin cartera, encargado de Aguas. Mamani había sido "uno

${ }^{4}$ Ese bastón de mando tiene la cabeza de un cóndor (que es otra acepción de la voz aymara mallku). Al nuevo Presidente también se le impuso la medalla de Bolívar. En la misma ceremonia sería "condecorado con el Gran Collar del Cóndor de los Andes y con el Gran Collar de la Legión de Honor del Mariscal Andrés de Santa Cruz"; véase http://bolivia.com/Especiales/2006/transmisión_mando/joyas.asp. Debo a Pedro Tomé estos detalles adicionales. 
de los principales impulsores de la Guerra del Gas que terminó expulsando del país al ex presidente Gonzalo Sánchez de Lozada”. Walter Villarroel, nuevo ministro de Minería y Metalurgia, sindicalista "del sector de los cooperativistas mineros", había intervenido activamente "en las movilizaciones que en junio del 2005 obligaron a renunciar al entonces presidente Carlos Mesa" (La Razón, 24 de enero de 2006). El aymara David Choquehuanca era el nuevo ministro de Asuntos Exteriores, dirigiéndose ese día a la prensa en aymara y en quechua (El Pais, ibid.).

Tras dar a conocer el nuevo Gobierno, Morales firmó hasta ocho acuerdos de cooperación económica y educativa con el Gobierno de Venezuela, presidido por Hugo Chávez, quien había asistido a la ceremonia de Tiahuanaco y a la investidura en el Congreso. Por esos acuerdos, la compañía Petróleos de Venezuela se comprometía a vender a Bolivia 200.000 barriles de crudo mensuales. También donaría a Bolivia material de construcción para carreteras y un fondo con el que dotar " 5000 becas para estudiantes del campo”. En una declaración conjunta tras la firma de los acuerdos, Chávez y Morales anunciaron su compromiso a "'destruir el viejo régimen', al que [identificaban] con las políticas neoliberales, y a trabajar [por] el establecimiento [de la] ALBA, la Alternativa Bolivariana para las Américas", contraria al ALCA promovido por el Gobierno de los EE. UU. (El País, ibid.).

\section{PASADO Y FUTURO EN EL PROCESO DE CONSTRUCCIÓN DE LAS NACIONES}

En esos acontecimientos de enero de 2006 hay una articulación de elementos extraños entre sí en origen que merece nuestra atención: junto con los que hacen referencia al pasado prehispánico de Bolivia y el Perú (como la invocación al Sol y a la Madre Tierra, o la elección de las ruinas de Tiahuanaco como escenario para la ceremonia del 21 de enero) aparecen los característicos de las instituciones y prácticas políticas de las naciones contemporáneas de Occidente (como la república como forma de Estado; un congreso elegido democráticamente; o el acto de acatamiento al nuevo Presidente por el "Comandante en Jefe de las Fuerzas Armadas"). Contaban asimismo las realidades del orden político y económico supranacional actual, como expresiones de la denominada "Globalización" (v. g., la denuncia del "Imperio" y del "neoliberalismo", o la declaración de apoyo a la ALBA de Hugo Chávez de Venezuela).

Para una aproximación comparativa a los movimientos nativistas y nacionalistas actuales, es significativa esa invocación contemporánea a la época precolonial de un país andino como Bolivia, y haberla hecho en el marco de un Estado definido entonces (según la constitución de 1967, reformada 
en 1993-1994) como una "república unitaria, multiétnica y pluricultural" y, en la actualidad, como un "Estado unitario social de derecho plurinacional comunitario".

Esos días de enero, el pasado prehispánico fue transportado ritualmente al presente, como si se quisiera generar con él, casi cinco siglos después, la misma energía (real o supuesta) que esa condición antigua hubiera tenido en su momento. La población originaria en el país andino (la que encontraron los conquistadores españoles del territorio en el siglo XVI) es todavía mayoritaria en él. En el censo de 2001, se identificaba como tal hasta cerca del 62,5\% de los mayores de 15 años. Y aparte los diferentes rasgos físicos y signos personales externos (v. g., en el atuendo y en el ornato del cuerpo), que pueden variar mucho de región en región, y de tiempo en tiempo, sigue siendo notable en esa población — particularmente en la alta Bolivia- la singularidad de hábitos, organización, ritos, creencias y hasta cultura material. Tiene que llamar poderosamente la atención que estas tradiciones originarias estén hoy lo bastante vivas como para influir en la investidura del presidente de una república, que es una institución europea; cuanto más que esa influencia se haga mediante símbolos en principio ajenos - y hasta contrarios - a la historia de Occidente en América. Un lector de periódicos - o incluso un turista- de Europa o los EE. UU., no mal intencionado pero poco informado, podría pensar que tales modos, usos y referentes no occidentales, correspondiendo a una alteridad cultural tan arraigada en otra época, están fuera de lugar y de tiempo en un mundo como el nuestro, al haber sido hace mucho superada esa diferencia por la racionalidad del progreso de la Historia; la misma que parece enseñar que las formas de vida actuales de las sociedades occidentales han resultado ser las más adecuadas para el bienestar de la humanidad y, por consiguiente, las que las demás sociedades, tarde o temprano, debieran emular.

Ese progreso, sin embargo, ha sido y es, en realidad, más complejo y, desde luego, nada necesario; como ya empezaran a advertirlo los historiadores de la escuela de los Annales francesa en la primera mitad del siglo XX (L. Febvre, M. Bloch y, especialmente, F. Braudel). Los efectos de los acontecimientos históricos tienen distinta duración, según cuáles fueren éstos y cuál, su contexto (definido, a su vez, por otros acontecimientos): desde lo efímero de una experiencia personal a lo secular de las costumbres, las creencias, las instituciones y las relaciones con el medio. Por si eso no dificultara ya bastante el análisis, los efectos duraderos de un hecho histórico pueden no manifestarse indeleble e irreversiblemente, sino periódicamente (como

\footnotetext{
${ }^{5}$ Según cifras del Instituto Nacional de Estadística de Bolivia; información disponible en http://www.ine.gov.bo.
} 
son, por ejemplo, las crisis económicas en los países industrializados; o algunas revitalizaciones históricas y culturales, que es el tema que nos ocupa).

Mucho antes que los fundadores de la escuela de los Annales, Karl Marx apuntó una idea congruente con esta complejidad del tiempo vivido: que la historia se repite, si bien como "farsa" (Marx 1971: 11). El fundador del materialismo histórico lo escribió pensando en casos como el golpe de Estado de Luis Bonaparte en la Francia de 1851: casos en que se producen hechos que recuerdan a otros anteriores, pero precisamente porque los protagonistas de la acción desean que así sea, como queriendo convocar a los mismos efectos, a la misma energía histórica que, a juicio de ellos, habían producido tales acontecimientos anteriores.

La palabra "farsa" empleada por Marx para hacer comprender este fenómeno no debiera inducirnos a error. No por escenificados — como si de una obra teatral se tratara- esos hechos fueron menos reales, como tampoco sus consecuencias. Y era sincero el deseo de los personajes intervinientes por hacer revivir el pasado (real o supuesto) como la mejor manera de hacer frente a un presente problemático. Eso es lo esencial, a mi juicio, de lo que en antropología se conoce como "movimiento de revitalización": una forma de cambio cultural, emprendido conscientemente y para el corto o medio plazo, que sería definida y explicada un siglo después de ese estudio de Marx a partir de experiencias de sociedades no occidentales que habían sufrido los efectos más destructivos del colonialismo. Pero la pervivencia o recurrencia de tales efectos más allá del momento histórico del colonialismo puede provocar igualmente, como reacción, uno o más movimientos de la misma naturaleza; más aún si sus impulsores entienden que ese momento histórico no ha terminado aún, o ha vuelto.

Debida originalmente al antropólogo estadounidense Anthony Wallace (1956) sobre la base del movimiento religioso de Handsome Lake entre los iroqueses del siglo XIX, esta teoría más general presupone que la sociedad o comunidad donde se produce la revitalización es una formación que, aunque históricamente constituida, ha dispuesto durante largo tiempo de medios propios de reproducción de su orden cultural separados de los de otras sociedades o comunidades con las que ha entablado contacto. Por tales medios de reproducción cultural cabe referirse naturalmente al régimen de subsistencia, pero también a la reproducción de la consciencia colectiva mediante mitos, ritos, creencias y otros productos de simbolización (v. g., una bandera, un himno), así como a la estructura del poder político. Bajo fuerzas exógenas de efectos muy destructivos — como lo fueron las del colonialismo- estos medios estructurales pueden quedar reprimidos y neutralizados, pero no anulados o extinguidos, o no todos ellos, y entonces, en coyunturas históricas favorables, que pueden no ser previsibles — como 
la dirección o inducción de un dirigente carismático-, tales instituciones pueden servir de base a una transformación que, inspirándose en una interpretación de un pasado más o menos remoto (sobre el que se legitiman esas estructuras), aspire a hacer frente a condiciones difíciles del presente para asegurar la continuidad de esa reproducción, que paradójicamente ya estaría asentada sobre principios distintos: los mismos que explican o desencadenan la revitalización. Esta paradoja es característica de tales movimientos: se impulsa un cambio histórico y cultural apelando a una continuidad o una recuperación del pasado.

Marx, en la misma obra sobre el golpe de Estado de Luis Bonaparte, también apuntó que la historia, si bien la hacen los hombres (esto es, seres humanos concretos, de carne y hueso), no la pueden hacer como ellos quisieran: "Die Menschen machen ihre eigene Geschichte, aber sie machen sie nicht aus freien Stücken, nicht unter selbstgewählten, sondern unter unmittelbar vorgefundenen, gegebenen und überlieferten Umständen" (Marx 1972, VIII: 115); "los hombres hacen su propia historia, pero no la hacen arbitrariamente, bajo circunstancias elegidas por ellos mismos, sino bajo circunstancias directamente dadas y heredadas del pasado", en la traducción de O. P. Safont (1971: 11) .

No pueden hacer su propia historia porque han de actuar en unas condiciones que son el efecto combinado de las acciones de quienes les precedieron, pero no sólo de su misma generación o de la anterior. "La tradición de todas las generaciones muertas —añadió Marx ( $i b i d$.) — oprime como una pesadilla el cerebro de los vivos". Y en esas "generaciones muertas" hay que incluir, naturalmente, tanto las del pasado reciente como las del remoto. En el caso de Bolivia, las generaciones muertas del pasado reciente son las que han conocido, desde el siglo XIX, el proceso de construcción de un Estado nacional. La revitalización del pasado prehispánico, como reacción al colonialismo, tiene así que vérselas, de manera dialéctica, con ese proceso de construcción: un producto de la modernidad que, en principio, parece contradictorio con el fenómeno de la revitalización.

${ }^{6}$ Tanto Claude Lévi-Strauss (1968: 24) como Fernand Braudel (1958: 92), fieles a un estructuralismo mecanicista, de hombres autómatas, interpretaron el pasaje citado como "Los hombres hacen la historia, pero no saben que la están haciendo". Paradójicamente, en la traducción francesa de Éditions Sociales, se lee: "Les hommes font leur propre histoire, mais ils ne la font pas arbitrariament, dans des conditions choisies par eux, mais dans des conditions directement données et héritées du passé" (Marx 1945). Doy las gracias a Ana Rabe por confirmarme que la expresión metafórica de Marx "aus freien Stücken" viene a querer decir en español "voluntariamente/espontáneamente/por libre decisión", clarificando de este modo el sentido del adverbio "arbitrariamente" empleado por Safont. 
La paradoja conduce a la segunda razón apuntada del interés por esos acontecimientos de enero de 2006 (así como por los subsiguientes, hasta hoy), ya que han ocurrido en un país que, a semejanza de la España actual (y de otros países, como Bélgica o el Reino Unido), ha sido calificado de Estado no "nacional" sino "unitario, pluricultural y multiétnico" y, más recientemente, de "Estado unitario social de derecho plurinacional comunitario": un tema que ofrece su propia problemática, tanto teórica como práctica, esto es, tanto a la investigación como a las formas de vida de la población que vive en unas condiciones políticas caracterizadas de esa manera.

Hay, sin duda, parecidos entre el caso español y el boliviano. Es fácil apreciar, por ejemplo, una clara diversidad lingüística y de usos y costumbres en uno y otro país. No hace muchos años que Jordi Pujol, siendo presidente de la Generalitat de Cataluña, declaraba en una entrevista en RTVE que España no es una nación, mientras que Cataluña sí lo es. Explicó que España es "una realidad formada por varias naciones", entre las que hay una historia común, así como mezcla de población e intereses económicos compartidos: "una comunidad" de la que Cataluña forma parte, pero no "una nación" (El País, 7 de octubre de 1998). En noviembre de 2005, el sucesor de Jordi Pujol, el socialista Pasqual Maragall, señalaba que España es "una nación de naciones, que tiene un Estado"; entendiendo por nación "un sistema compartido de sentimientos" ( $A B C$, Madrid, 6 de noviembre de 2005; Cf. Elorza 2005). La idea había quedado reflejada unas semanas antes en el nuevo estatuto de Cataluña aprobado por el Parlament de la Generalitat por mayoría abrumadora: en su preámbulo se afirmaba que "Catalunya considera que Espanya és un Estat plurinacional", en el cual Cataluña es una "nació", entendida en el sentido de "poble", que mantiene "relacions" con las demás naciones o pueblos:

Aquest Estatut defineix les institucions de la nació catalana i les seves relacions amb els pobles d'Espanya en un marc de lliure solidaritat amb les nacionalitats i les regions que la conformen, compatible amb el desenvolupament d'un Estat plurinacional (Parlament de Catalunya 2005: 1-2).

Junto con las semejanzas con Bolivia, cabría esperar que entre España y el país andino se dieran asimismo diferencias, ya que el registro histórico y el antropológico no son como un océano en el que se den idénticas gotas de agua. Pero tendría importancia epistemológica saber si tales diferencias — como las semejanzas - son o no significativas; en otras palabras: saber si podríamos entender —y en qué sentido, y hasta qué punto- el caso español (por seguir con este ejemplo, tan cercano a mí y a la mayoría de los lectores de la $R D T P$ ) como análogo al boliviano, o viceversa.

Ya antes de la redefinición constitucional de 1994 y 2009, conocidos 
especialistas plantearon que la realidad de la república fundada por Bolívar no es objetivamente una realidad nacional sino otra distinta, plurinacional o pluricultural (Salomon 1982a: 84-85; 1982b; Rivera Cusicanqui 1986: 1-5; 2007: 101-110; Barnadas 1990b; 2009); como también lo sería España. De este supuesto debería partir la comprensión de su historia, así como sus problemas actuales y su futuro. En coherencia con lo cual, la población indígena del país andino, por ejemplo, que vive mayoritariamente en comunidades rurales, no debería ser concebida o tratada como una clase social — "el campesinado" - en un Estado nacional; sino más bien como un conjunto de naciones propias y antiguas de por sí sometidas por la fuerza a un Estado, la república de Bolivia, que es ajeno a sus tradiciones por estar definido, hecho y controlado por otra nación, la colonizadora.

Desde esta perspectiva, las victorias electorales del MAS, las acciones políticas de Evo Morales, y hasta la misma personalidad de éste, a caballo entre su ascendencia aymara y su vida adulta como cocalero militante en El Chapare, habría que entenderlas como incongruencias históricas que pudieran conducir a Bolivia a una nueva forma de cooptación colonialista y por ende, a la injusticia y el conflicto. Como ha apuntado Rivera Cusicanqui,

De algún modo, la adopción [por el MAS] de ideas como pluralismo étnico y lucha por la soberanía encubren una agenda oculta de la clase política criolla, de continuar monopolizando la "capacidad de nombrar y de normar" [...], dando "vOz a los sin voz" y neutralizando así sus visiones de futuro, sus prácticas organizativas y sus definiciones de la política y el buen gobierno (2007: 106).

Cabe pensar, en efecto, que Morales, no obstante su origen y su retórica sobre el pasado prehispánico, actuó siempre como un típico dirigente campesino de izquierdas en un Estado nacional: participando en luchas sindicales, de clase; aliándose en la oposición con marxistas en su estrategia política; y, una vez en el Gobierno, iniciando una agresiva política exterior de corte guevarista que le ha llevado a apoyar los idearios continentales de la Venezuela de Hugo Chávez y la Cuba de Fidel Castro, alarmando con ello a compañías internacionales (v. g., la hispano-argentina REPSOL-YPF) con fuertes inversiones en el país.

El también aymara y ex-guerrillero Felipe Quispe representaría más genuinamente la otra Bolivia, la más auténtica por ser la más antigua, la heredera de "la república de indios" de tiempos de la colonia (Rivera Cusicanqui 1986: 1). Quispe no sólo se expresa con frecuencia en su lengua materna sino que, además, tiene muy claro que los intereses de su "nación" — la "nación aymara" - son diferentes y hasta contrarios a los de otras naciones, especialmente la de los europeos que llegaron en el siglo XVI. En una entrevista concedida en julio de 2005, por ejemplo, declaró: 
La nación aymara también piensa autodeterminarse como nación con su propio ejército, con sus propias autoridades, con nuestros propios símbolos, insignias. Todo lo que tenemos, todo lo que nos rodea... porque mirá, somos una nación, tenemos nuestro territorio, tenemos nuestra tierra, tenemos nuestra religión, idioma, cultura, filosofía, leyes y también tenemos usos y costumbres, entonces sobre eso nos basamos, pero sin embargo Bolivia no tiene nada. Bolivia está anclada sobre nuestro territorio, Bolivia no tiene su propio idioma porque ese idioma es de los españoles, yo mismo estoy hablando ese idioma. No tiene su propia religión, la religión que han traído es muy sangrienta, usted entra a una iglesia y ahí va a estar sacrificado un señor, ese pobre está torturado, está pura sangre, ese tipo de religión tiene. Nosotros, sin embargo, tenemos nuestras wak'as, nuestras illas, nuestros mallkis, Pachakamac, el padre sol, la madre luna, la Pachamama, todos los uywiris (los que te crían), no hay tal sangre, nuestra religión no es sanguinaria. [...] Lo que más nos perjudica es el partido MAS (Movimiento Al Socialismo) de Evo Morales porque ellos quieren hacer el remiendo a ese sistema envejecido, a un sistema que oprime a la nación indígena ${ }^{7}$.

Esta valoración contrasta cualitativamente con otras reflexiones que se han hecho en décadas recientes acerca de las naciones y los nacionalismos en el mundo contemporáneo; no necesariamente sobre el caso concreto de Bolivia, pero sí de otros Estados del mundo reconocidos por la ONU. Reflexiones como las de Hobsbawm y Ranger (1983), Hobsbawm (1990), Anderson (1991), Daniel (1995), López Calera (1995), Savater (1996) o Gellner (1997). Haciendo abstracción de las diferencias entre sí que uno puede encontrar en ellas —en mi opinión, accesorias en lo que toca a este ensayo-, en todas se llama la atención sobre el voluntarismo, el contexto intelectual y las circunstancias históricas concretas que están en el origen de tales nacionalismos; partiendo del concepto mismo de nación (la "comunidad imaginada" por los nacionalistas, como la ha definido Anderson), que se opone diametralmente al concepto objetivo, genealógico, avalado por una historia larga, que sugieren las palabras de Quispe.

\section{PARTICIPACIÓN VS. DESCENDENCIA EN LA NACIÓN}

La contraposición entre ambos conceptos expresaría una barrera cultural infranqueable si esas palabras procedieran de un milenario pensamiento político aymara. Pero recuerdan más bien a las de Johann G. Herder (1959), al oponer un concepto de nación como el de Quispe al esgrimido por los revolucionarios franceses de 1789 , convencidos éstos de la teoría del contra-

\footnotetext{
${ }^{7}$ Felipe Quispe entrevistado por Iván Ignacio, del Consejo Andino de Naciones Originarias, el 13 de julio de 2005; en http://www.pusinsuyu.com/html/entrevistas.html (documento consultado en octubre de 2007).
} 
to social defendida por pensadores como Thomas Hobbes (1968) y, sobre todo, John Locke (1948). Los dos conceptos pueden entenderse, por consiguiente, como productos de una ideología nacionalista occidental en un determinado contexto histórico; lo que les diferencia es el criterio propuesto, en tal contexto, de pertenencia a la nación imaginada de que se trate.

A primera vista parecería que el concepto voluntarista y participativo de la nación es más propio de una monarquía constitucional como la española que de un país como Bolivia, en el que todavía una buena parte de la población no habla la lengua de los colonizadores. Sin embargo, es también de aplicación en este caso. No había una "nación aymara" en el sentido político mencionado por Quispe antes de que los colonizadores llegaran, aunque sí una tradición cultural aymara que ha llegado hasta nuestros días; tradición que incluía una forma de reproducción del orden social y político. Lo mismo cabe decir de las demás tradiciones culturales prehispánicas. La percepción de la actual diversidad del país como compuesta, entre otros elementos, de "naciones y pueblos originarios" es condición de la revitalización indianista en curso y, por tanto, un fenómeno de nuestro tiempo.

Antes de la conquista española, el centro-sur andino estaba dividido en un conjunto de formaciones sociales de lengua aymara, quechua y tupiguaraní, entre otras, la mayoría de las cuales estaba integrada en una de las cuatro partes en que se dividía el imperio inca: el qollasuyu. Los españoles del siglo XVI —v. g., Cieza de León 1984, 1985; Álvarez 1998; Acosta 2008- se refieren a ellas con el término de "naciones", como sinónimo de "gentes", "naturales" o, simplemente, "indios" de tal o cual "provincia": "los collas", "los charcas", "los uros", "los lipes", "los atacamas". En términos de antropología política, estos pueblos estaban organizados como sociedades estratificadas bajo jefes o "señores" o "caciques" hereditarios (los de lengua aymara o quechua) o como sociedades tribales (la mayoría de los pueblos amazónicos y tupi-guaraníes). Con anterioridad a la formación del imperio inca, otro Estado arcaico, el de Tiwanaku, había comprendido lo que hoy es la alta Bolivia, el sur del Perú y el norte de Chile. La ciudad de Tiwanaku, capital de este Estado, hoy Tiahuanaco, pudo no haber sido aymara (Kolata 1993: 34-35). En todo caso, tratándose de una cultura ágrafa, es difícil conocer en detalle su organización política, más aún ritos como el de la entronización del nuevo rey o emperador. Entre los incas, la subida al trono del nuevo soberano coincidía con el matrimonio con su hermana, y es posible que la ceremonia la oficiara un sumo sacerdote, como el del templo del sol en Cusco, la capital. Pero es sólo hipotética, en el mejor de los ca-

\footnotetext{
${ }^{8}$ Véase, por ejemplo, Fernández Juárez (2004) para el caso de la cosmología, así como el ensayo del mismo autor en el presente volumen para el ritual.
} 
sos, la extrapolación a tiempos de Tiwanaku del orden político y ritual inca, varios siglos posterior. La ceremonia del 21 de enero de 2006 en Tiahuanaco se ajusta bien, por eso, a lo que Hobsbawm y Ranger llamaran "una tradición inventada", con el fin de satisfacer una necesidad política derivada de cambios históricos profundos y rápidos.

En mayo de 1811, el mismo lugar había servido de escenario a otro acto ceremonial, surgido de una necesidad política diferente, aunque también derivada de cambios profundos y rápidos. En vísperas de la batalla de Guaqui, entre patriotas y realistas, el comisionado de la Junta de Buenos Aires, Juan José Castelli, conmemoró en Tiahuanaco, ante una multitud indígena, el primer aniversario de la revolución emancipadora de España con una "Declaración [...] sobre la liberación de los indios", en la que les anunciaba el trato igual que a los criollos les correspondía por derecho de ciudadanía, así como el reparto de tierras y el establecimiento de escuelas (Goldman 1998: 48-49).

La república de Bolivia, como la del Perú, se constituiría quince años más tarde sobre estas bases ideológicas —educación, propiedad privada, ciudadanía individual asociada a la residencia-, que eran las de la nación mediante contrato social. La "Nación española" establecida por las Cortes de Cádiz en 1812 tenía un fundamento homólogo. Esas bases no eran las de los pueblos originarios en Bolivia y el Perú, que fueron excluidos del contrato social. Además, éste les fue impuesto a los no-originarios (mayoritariamente, propietarios de tierras y minas varones de ascendencia española, quienes tenían bajo su poder a los originarios) por la fuerza del ejército libertador. El "nacionalismo criollo" en América tan ensalzado por Anderson (1991: 48) apenas tuvo nada que hacer en ese importante salto cualitativo en la historia de la región andina central. Con el tiempo, sin embargo, y a lo largo de más de un siglo — repleto de vicisitudes-, la nación así constituida fue ampliando su estrecha base social, incorporando por ello a la ciudadanía, mediante legislación o por la vía de los hechos, especialmente en los procesos electorales, a nuevas partes contrayentes, como los artesanos y los pequeños comerciantes con ciertos ingresos anuales, que supieran leer y escribir (Irurozqui 2000, 2006).

La participación de los originarios como sujetos con plenos derechos tardaría en llegar. Hasta bien entrado el siglo xx, el papel que les estaba reservado, como a otros sectores marginados, era sobre todo el de fuerza movilizada por los candidatos en las elecciones. No obstante, sus protestas y rebeliones fueron frecuentes, especialmente a partir de 1860, con la reactivación de la minería y, por tanto, del interés por las tierras de las comunidades, que no formaban parte de las haciendas (Albó 1990a: 153-156).

En las décadas de 1920 y 1930, un movimiento indigenista revolucionario, con centro en el Perú, tenía entre sus objetivos la revitalización de la 
organización inca, considerada entonces como un caso de socialismo avant la lettre. Si bien el movimiento fracasaría, pocos años después — de 1932 a 1935-, la Guerra del Chaco contra Paraguay obligaría al Gobierno boliviano a movilizar un ejército de 200.000 hombres que, por vez primera, afectaba simultáneamente a todo el espectro étnico y social del país andino en su conjunto (Guzmán 1990: 238; Albó y Barnadas 1990: 185-186). Tras la derrota -y la consiguiente pérdida de buena parte de ese extenso territorio del sureste-, la población indígena movilizada participaría activamente, junto con los demás sectores marginados, en el movimiento conducente a la llamada "Revolución Nacional" de 1952.

Impulsada principalmente por el MNR y la Central Obrera Boliviana (COB), la Revolución significó una ampliación de la comunidad nacional de 1826 como nunca antes se había intentado. El derecho al sufragio se hizo universal; hasta entonces, había sido sólo censitario. En consonancia con ello se creó un nuevo ejército, calificado de "popular". Las minas fueron nacionalizadas, pasando a depender de la empresa estatal "Corporación minera boliviana" (COMIBOL). Para la extracción y comercialización del petróleo se fundó la igualmente estatal "Yacimientos Petroleros Fiscales Bolivianos" (YPFB). En el campo, fueron reconocidas las ocupaciones de las haciendas por parte de los indígenas (llamados "campesinos" desde 1945), procediéndose después a una reforma agraria que las parceló. También se fomentó la sindicalización y la formación de cooperativas como instrumentos de articulación con el Estado, y se impulsó la colonización del Oriente, con centro en Santa Cruz.

La reforma educativa era otra asignatura pendiente: "de una educación de castas a una educación de masas”, rezaba el lema de un plan integral de instrucción laica y mixta desde la fase pre-escolar a la universitaria y la técnico-profesional, de construcción de escuelas, incremento en el número de maestros y lucha contra el analfabetismo (el 70\% en 1952): "la acción alfabetizadora se hará en las zonas donde predominan las lenguas vernáculas, utilizando el idioma nativo como vehículo para el inmediato aprendizaje del castellano como factor necesario de integración lingüística nacional" (art. 115 del Código de Educación) (Guzmán 1990: 315-455; Klein 1985: 277-298; Albó y Barnadas 1990: 179-225; De Mesa et alii 1998: 615-639). Las ruinas de Tiahuanaco fueron interpretadas como las de la capital de un gran Estado aymara prehispánico de larga historia y un importante símbolo nacional (Ponce Sanginés 1981: 27-29, 48, 54, 60-67; Guzmán 1990: 115).

Sin embargo, la Revolución fracasó en muchas de las aspiraciones de

9 El número total de habitantes de Bolivia no llegaría a los tres millones. El censo de 1950 arrojaría una cifra de 3.019.031 (Guzmán 1990: 313-314). 
sus impulsores y traicionó diversas expectativas de sus partidarios. La oligarquía de latifundistas y mineros (conocida como "La Rosca") dio paso en gran medida a una oligarquía de partido, el MNR, que intentaría mantenerse en el poder mediante prácticas ilegales, la corrupción y la represión. El nuevo "ejército popular" acabó generando una "hipertrofia militar" en la administración. Las nacionalizaciones en las minas y en los yacimientos de petróleo no pudieron evitar, por falta de capitalización, una nueva dependencia de empresas extranjeras, especialmente de los EE. UU. La parcelación de las haciendas favoreció, en las zonas más pobladas, la minifundización y, ulteriormente, la emigración a las ciudades y el desempleo o subempleo en ellas; sin que estos efectos se vieran compensados por sensibles mejoras técnicas en la producción agraria (Barnadas 1990a).

En noviembre de 1964, con el golpe de Estado de René Barrientos, vicepresidente de la República, los militares intentaron reconducir la Revolución, asumiendo el control de las empresas estatales y emprendiendo reformas administrativas y constitucionales. Sin embargo, también favorecieron la reorientación de la economía hacia el sector privado y el alineamiento con los EE. UU., con lo que la Revolución se alejó aún más de quienes la habían apoyado y perdía mucho de su carácter nacionalista (Albó y Barnadas 1990: 229-261).

En el campo, mediante el llamado "Pacto militar-campesino", el Gobierno asumió el papel vertebrador y clientelista del MNR en el acuerdo político-sindical establecido en 1952. En la práctica, el cambio no supuso otra cosa que una intromisión mayor del Gobierno en la organización y dirección de los "campesinos" — suficiente para contener y luego derrotar la guerrilla del Che Guevara-, al tiempo que una serie de violaciones del acuerdo con el MNR; entre otras, el aumento de la presión fiscal, la burocratización en la concesión de títulos de propiedad derivados de la reforma agraria, y la desviación de recursos presupuestarios en beneficio de empresas agrarias privadas orientadas a la exportación (Yashar 2005: 163-165).

Fue sólo entonces, en este contexto de fracaso y traición a la "Revolución Nacional", no antes, cuando se descubrió el significado político de la diversidad cultural del país en términos de nacionalidades indígenas - lo que Xavier Albó (2007: 342) ha llamado "la emergencia étnica"—, iniciándose con ello el debate sobre una reconstitución de Bolivia como Estado plurinacional. Uno de los que hizo tal descubrimiento, en principio el más persuasivo, fue el abogado y escritor Fausto Reinaga. Antiguo militante y parlamentario del MNR, e influido por el marxismo, "en 1962 fundó el Partido de Indios Aymaras y Kechuas (PIAK), transformado después en Partido Indio de Bolivia, como el instrumento de la 'revolución india' que habría de conducir a la construcción de una Bolivia bajo hegemonía india” (Cárdenas 2002). 
Jóvenes estudiantes aymaras de enseñanza secundaria y universitaria en La Paz conocieron allí el pensamiento de Reinaga y a continuación lo difundieron en sus comunidades de origen, así como entre las bases de la organización sindical en el Altiplano que había creado y controlado el MNR. En esas comunidades y bases apenas se recordaba quién había sido Tupaq Katari (Javier Hurtado Mercado en Yashar 2005: 170). Emergieron entonces dos maneras distintas de ver el futuro político de la población indígena en Bolivia: la "indianista" en las ciudades, de Reinaga, y la "katarista" en el campo (Van Cott 2003: 40-41; Yashar 2005: 167-171). De la segunda, que se revelaría ulteriormente como la mayoritaria, surgirían Jenaro Flores — cofundador y primer presidente de la CSUTCB, en 1979- y Víctor Hugo Cárdenas, fundador del MRTKL y con el tiempo vicepresidente de la República. Los kataristas advertían en la posición humillada de los indígenas la operatividad de un criterio de discriminación por etnias o culturas en combinación con otro por clases sociales. En julio de 1973, bajo la dictadura de Bánzer, varias organizaciones kataristas difundieron el llamado "Manifiesto de Tiahuanaco":

Nosotros, los campesinos quechuas y aymaras lo mismo que los de otras culturas autóctonas del País, [...] nos sentimos económicamente explotados y cultural y políticamente oprimidos. En Bolivia no ha habido una integración de culturas sino una superposición y dominación, habiendo permanecido nosotros en el estrato más bajo y explotado de esa pirámide. Bolivia ha vivido y está viviendo terribles frustraciones. Una de ellas, quizás la mayor de todas, es la falta de participación real de los campesinos quechuas y aymaras en la vida económica, política y social del País. Pensamos que sin un cambio radical en este aspecto será totalmente imposible crear la unidad nacional y un desarrollo económico dinámico, armónico, propio y adecuado a nuestra realidad y necesidades (en Rivera Cusicanqui 1986: 177).

El manifiesto contrariaba la Declaración de Castelli de 1811. En él se reconocía la contribución hecha por el MNR, especialmente mediante la concesión del derecho universal al sufragio y la Ley de Reforma Agraria. El MNR tuvo así — se afirmaba— "la posibilidad histórica de convertirse en un partido que fuera instrumento de la liberación campesina". Sin embargo, "todo se frustró debido, sobre todo, a que elementos de la reacción derechista y sin ninguna sensibilidad social, se incrustaron en las filas de este partido y lograron detener el proceso de nuestra liberación". Había quedado pendiente el desarrollo técnico de las comunidades y una política sostenida de apoyo a los precios agrarios con la que sustituir importaciones. La enseñanza que se impartía en las escuelas rurales era "ajena a nuestra realidad no sólo en la lengua, sino también en la historia, en los héroes, en los ideales y en los valores que transmite". Los firmantes del manifiesto abogaban por un partido político y una organización sindical, propios de "los campesinos" que 
pusieran por obra las reformas necesarias en estos y otros ámbitos, en alianza con los demás sectores oprimidos del país:

Los mineros, los fabriles, los obreros de la construcción, del transporte, las clases medias empobrecidas... son hermanos nuestros, víctimas bajo otras formas, de la misma explotación, descendientes de la misma raza y solidarios en los mismos ideales de lucha y liberación. Solamente unidos lograremos la grandeza de nuestra patria (ibid.: 180-185).

Nótese esa arenga nacionalista final, coherente con el hecho de que entre "los héroes" a recordar no figurara José Gabriel Condorcanqui (más conocido como "Tupaq Amaru II"), el jefe supremo, en el Perú, del levantamiento en el que participara Tupaq Katari, en el siglo XVIII. La proclama terminaba con un llamamiento a la Iglesia Católica y a las Iglesias Evangélicas para que respaldaran "este gran ideal de liberación de nuestro Pueblo Aymara y Quechua” (ibid.: 185); respaldo que se conseguiría en gran medida, así como el apoyo de diversas ONG nacionales e internacionales (Yashar 2005: 174179). También tendría su influencia el gran desarrollo de la etnografía en la década de 1970, en el que muchos de sus impulsores (J. B. Casagrande, P. L. van den Berghe, G. P. Primov, J. H. Hickman) ya concebían el Perú, Bolivia y Ecuador como una realidad postcolonial dividida en primer término por categorías étnico-culturales antes que por fronteras estatales (Salomon 1982a: 84-85). Éste sería el trasfondo de la fundación de la CSUTCB en 1979, tras la caída de la dictadura de Bánzer.

Por esos mismos años empezaba a desarrollarse en las tierras bajas del este del país un movimiento paralelo de "emergencia étnica". No era un movimiento katarista, aunque también tuvo como causa última la Revolución Nacional de 1952; en concreto, el plan de colonización de este territorio impulsado por la Revolución, que atentaba contra el orden político y económico indígena. Después de la caída de Bánzer, los afectados empezarían a rebelarse contra el plan, contando también ellos con el apoyo de ONG nacionales e internacionales, antropólogos y sociólogos, la Iglesia Católica (especialmente jesuitas) y el protestante Instituto Lingüístico de Verano. El protagonismo principal indígena en este segundo proceso correspondió a Bonifacio Barrientos, "capitán grande" de los guaraní-isoseños familiarizado con la Administración desde la década de 1930, hasta culminar en la constitución en 1982 de la "Confederación Indígena del Oriente Boliviano” (CIDOB). Integrada en principio por guaraní-isoseños, ayoreos, guarayos y chiquitanos, la CIDOB reclamaba autonomía territorial para estos pueblos indígenas, participación en el Estado y mejoras en la salud y en la educación. Aunque la población de estos pueblos era escasa en comparación con la de aymaras y quechuas, la CIDOB adquiriría una influencia 
comparable en la difusión del concepto de Bolivia como Estado plurinacional (Albó 1990b: 289-295; Yashar 2005: 190-218; Postero 2007: 44-54). En octubre de 1996 lograrían del Gobierno MNR-MBL-MRTKL la promulgación de la Ley del Instituto Nacional de Reforma Agraria (INRA), por la que el Estado reconocía el derecho de los pueblos indígenas a sus territorios colectivos ("tierras comunitarias de origen") (Yashar 2005: 217-218; Postero 2007: 53).

Un tercer foco de "emergencia étnica" fue el departamento de Cochabamba, en el centro del país. Surgió más tarde que los otros dos, como consecuencia del denominado "Decreto Supremo 21.060" del Gobierno de Víctor Paz Estenssoro (agosto de 1985), que iniciaba una "Nueva Política Económica" con la que hacer frente a un grave deterioro de las finanzas públicas y de la balanza de pagos, una enorme deuda externa e hiperinflación. Con la abierta hostilidad de la COB, y el asesoramiento del economista estadounidense Jeffrey Sachs, el Gobierno hizo una reforma monetaria y tributaria en profundidad; decretó la libertad de comercio; ordenó privatizaciones o liquidaciones de empresas estatales, especialmente en la minería; y abrió el país al capital extranjero (Guzmán 1990: 457-470; De Mesa et alii 1998: 695-706).

Tal "Nueva Política Económica" significaba el entierro definitivo de la política nacionalizadora y redistribuidora de la Revolución de 1952 y el comienzo de lo que pronto se conocería como "neoliberalismo" en el país. Uno de sus primeros efectos fue la emigración ("deslocalización") a las periferias de las ciudades y los valles productores de hoja de coca de numerosas familias que habían dependido directa o indirectamente de la minería en el Altiplano. A finales de la década de 1980, Evo Morales, quien se había instalado en El Chapare antes del Decreto 21.060 (Sivak 2008: 59-79), se puso al frente de la resistencia de los cocaleros a los planes del Gobierno y de los EE. UU. contra el cultivo de la hoja. En la década siguiente, al justificar éste apelando a las tradiciones culturales prehispánicas, puso en circulación otro discurso étnico (Yashar 2005: 184-185).

El cuarto y último foco de discurso étnico, ya en esa década de 1990, fue el de las provincias centrales y meridionales del Altiplano. Independiente de los anteriores - aunque no de ONG, como el Taller de Historia Oral Andina (THOA) y sus programas de radio, Oxfam y la Inter-American Foundation-, este movimiento pronto mostró sus diferencias con el de los aymaras del norte del Altiplano y el departamento de La Paz, así como con el de Morales en El Chapare. Rechazaba no sólo toda injerencia del Gobierno sino también la de grandes organizaciones sindicales como la CSUTCB, en la que los cocaleros ya eran mayoritarios desde 1994. Por contraposición a ellos, reivindicaba la autonomía de las comunidades locales y la conserva- 
ción de sus tradiciones, incluidas las organizativas (Yashar ibid.: 187-188; Sivak 2008: 125).

Al igual que el de Bolivia, el concepto de España como "Estado plurinacional" habría tenido como causas últimas no tanto las historias largas de sus distintas "naciones" cuanto el fracaso de -o la reacción contra- un proyecto de revolución nacional; en este caso, el de Cádiz de 1812. Como ha recordado recientemente Pérez Garzón (2009: 129-136), los impulsores de este proyecto no lograrían llevar a cabo las reformas legales, administrativas, sociales y económicas esperadas — no consiguieron vencer la oposición a ellas de la elite del poder heredera del Antiguo Régimen-, al tiempo que tenían que enfrentarse con los nacionalismos igualmente emergentes en varias de sus partes (Cataluña, Vizcaya, Galicia), estimulados por el romanticismo. Éste influiría asimismo en el concepto de España y pronto el espíritu de 1812 —participativo y de base territorial - aparecería contaminado, y ulteriormente desplazado, por un nacionalismo historicista, de base genealógica, en deuda con el pensamiento católico.

La hegemonía de este nacionalismo historicista y católico español ${ }^{10}$ —que es lo que cabría entender por "españolismo" - no podía hacer sino más acusada todavía la concurrencia conflictiva con otros nacionalismos historicistas en el territorio del mismo Estado; hasta el extremo de hablarse desde éstos de un "colonialismo interior" (Barnadas 2009) contra las "naciones" correspondientes, al igual que en Bolivia y otros países de América, África y Asia ${ }^{11}$.

\section{LA REVITALIZACiÓN DE BOLIVIA}

Haya habido realmente o no colonialismo a este lado del Atlántico, los horizontes políticos de tales movimientos - la independencia como Estados

\footnotetext{
${ }^{10}$ Véase el ensayo de Juan Aranzadi en este mismo volumen.

${ }^{11}$ En 1991, a propósito de la independencia de Lituania, Jordi Pujol apuntó que la relación de Cataluña con España era como la que había tenido Lituania con la Unión Soviética antes de su independencia (El País, 9 de septiembre de 1991). En 1998, en el contexto del $50^{\circ}$ aniversario de la Declaración Universal de los Derechos Humanos por la ONU, el Departamento de Justicia, Economía, Trabajo y Seguridad Social del Gobierno vasco impulsó una campaña publicitaria de defensa de la autodeterminación de los pueblos. "Todos los pueblos tienen derecho a la libre determinación", rezaba uno de los anuncios. Unos meses antes, los partidos, sindicatos y otras organizaciones nacionalistas vascas, así como Izquierda Unida-Ezker Batua, habían suscrito un acuerdo en Estella por el que abogaban por el reconocimiento, por parte del Estado español, del "ámbito vasco de decisión", a cambio de que ETA, que había declarado una tregua, depusiera definitivamente las armas (El País, edición del País Vasco, 18 de noviembre de 1998).
} 
nacionales de las comunidades imaginadas, aunque formando parte de la Unión Europea- deberían adivinarse auscultando no tanto el discurso nacionalista que hace referencia a él cuanto el estado de esos medios propios de reproducción cultural de larga duración que he mencionado antes — contrapuestos a los de la formación social o comunidad con la que se ha estado en contacto- ante fuerzas desestructuradoras provenientes de ella.

Wallace distinguió cinco fases en el proceso completo en el que se inserta un movimiento de revitalización: 1) estabilidad cultural anterior a la presión exógena (en la teoría original de Wallace, derivada a menudo, pero no siempre, de la aculturación), 2) fase de presión exógena sostenida y efectos sobre el individuo, 3) fase de distorsión cultural, 4) movimiento de revitalización y 5) nuevo orden cultural (triunfante o fracasado el movimiento de revitalización).

Hace unos años tuve la oportunidad de estudiar el caso del Perú, donde se han registrado movimientos de revitalización recurrentes desde el siglo XVI hasta el Xx (Villarías-Robles 1997) ${ }^{12}$. Dejando aparte las coyunturas de crisis favorecedoras de cada uno de estos movimientos, las condiciones de larga duración que explican tal recurrencia son fundamentalmente tres. Hay, en primer lugar, una población originaria, mayoritaria en el centro y sur del interior del país, que cuenta con innegables medios propios de reproducción cultural, contrapuestos a los de otros sectores de la población y otros territorios. En segundo lugar, esta población indígena ocupa una posición claramente inferior en el orden social, político y económico de la República, como antes bajo el régimen colonial. Y hay, finalmente, un discurso revitalizador, una justificación — digamos "mítico-ideológica", expresada tanto por medios escritos como por tradición oral- que no sólo da sentido a esta doble situación (esto es, la identidad propia con respecto al Otro y su status inferior) sino que anuncia o promete su fin en un futuro cercano, cuando dicha población ocupará la posición de preeminencia de quienes ahora la detentan, descendiendo entonces éstos a la suya; en otras palabras: un vuelco social y político de ciento ochenta grados, conocido como pachakuti. Así entendían al menos los aymaras en los siglos XVI y XVII el "juyzio final" que les anunciaban los misioneros españoles.

El caso boliviano tiene, en principio, si se le compara con el peruano, algunas diferencias, que derivan de una historia distinta. No se da en Bolivia, por ejemplo, la misma recurrencia de revitalizaciones; lo que no quiere decir ausencia de levantamientos indígenas. Ya hemos visto que a partir de

${ }^{12}$ El movimiento político de Ollanta Humala conocido como "etnocacerismo", que estuvo cerca de vencer en las elecciones generales de 2006, sería tal vez el más reciente de ellos. 
1860, y hasta la Guerra del Chaco —incluso hasta la revolución de 1952-, las sublevaciones fueron frecuentes (Albó 1990a: 153-156). Pero salvo tal vez la encabezada por Zárate Willka, en el contexto de la guerra civil de 18981899 (Condarco Morales 1965), todas ellas respondieron a los intentos por privatizar y adueñarse de tierras comunitarias para satisfacer las demandas de la oligarquía hacendístico-minera en el poder. No fueron movimientos sobre bases de consciencia étnico-cultural frente a la de los blancos en el poder; tampoco generales, sino locales o provinciales.

No obstante lo cual, Bolivia reúne, como el Perú, varias condiciones estructurales necesarias para un movimiento de revitalización. La primera es, también aquí, una población originaria culturalmente autosuficiente que ha estado socialmente marginada desde el siglo XVI y que, al menos hasta la Guerra del Chaco, fue excluida de la nación constituida en 1826. Ha habido asimismo dirigentes carismáticos capaces de encabezar un movimiento de tal naturaleza; como los mencionados Fausto Reinaga, Jenaro Flores, Víctor Hugo Cárdenas y Bonifacio Barrientos. En la década de 1960, Reinaga puso incluso en circulación un discurso "mítico-ideológico" de salvación colectiva para la población indígena, llamando a "una revolución amáutica ${ }^{13}$ mundial" que no se produjo (Cárdenas 2002). Un planteamiento así no habría tenido apenas precedentes en la historia del país, a diferencia de la del Perú. García Linera (2008) ha calificado esta ausencia de "indianismo de resistencia".

Una condición adicional necesaria en las últimas décadas también la hemos visto en las páginas anteriores: la "emergencia étnica" surgida en cuatro focos distintos del país tras el fracaso, reacción o abandono del Estado nacional surgido de la revolución de 1952. El contexto internacional ha favorecido este proceso. Albó (2007: 342-343) ha llamado la atención sobre el impacto de movimientos de solidaridad transnacionales en torno a la defensa de los pueblos indígenas o preocupados por la situación de la mujer o el deterioro de la biodiversidad del planeta. La mayoría de estos movimientos - expresión de un nuevo internacionalismo- eran impensables antes del fin de la Guerra fría y el desmoronamiento del bloque soviético. También tuvieron importancia los preparativos en España para la conmemoración en 1992 del V Centenario del descubrimiento de Cristóbal Colón, que suscitaron un amplio rechazo entre la población originaria y otros sectores no hegemónicos de Bolivia, al igual que en otros países de América. Los pueblos indígenas en todo el mundo han sido, además, desde 1977, objeto de creciente atención por parte de Las Naciones Unidas y la Organización Internacional del Trabajo (OIT) (Martí i Puig 2007: 133).

\footnotetext{
${ }^{13}$ De la voz quechua amauta: filósofo, sabio (Lara 2007: 46).
} 
El declive mismo del Estado nacional como instancia de poder político es un fenómeno general en la historia de la humanidad de las últimas décadas. España tampoco ha escapado a este devenir, uno de los más elocuentes de la Globalización. Este declive debe mucho a la actividad de esos movimientos de solidaridad transnacionales — facilitada por el progreso técnico en los medios de información y comunicación-, así como al protagonismo cada vez mayor de instancias de poder supraestatales: la ONU, la Unión Europea, el FMI, el G-7, luego G-8, luego G-20, MERCOSUR, la ALBA de Hugo Chávez... No hay que olvidar tampoco el paralelo abandono de teorías sociológicas y antropológicas de fuerte corte universalista y evolucionista - las que Lyotard (1986) llamara "grandes relatos", como el marxismo evolucionista y el neo-evolucionismo no marxista-, que ha contribuido asimismo a la decadencia del Estado nacional. La consecuencia es que la diversidad cultural en un Estado nacional ya no se intenta aprehender acudiendo al concepto de "grados de desarrollo" respecto de una condición cultural de referencia, sino a categorías genealógicas del mismo rango ontológico, cada una con los mismos derechos a formar parte de la comunidad política. La pérdida de importancia política del Estado Nacional es, en efecto, el principal eslabón lógico que conecta la Globalización con los movimientos de revitalización recientes en el mundo - también en España-, estableciendo una relación sinérgica entre ambos fenómenos.

Lo distintivo y nuevo en el caso de Bolivia es la convergencia de todas estas condiciones estructurales necesarias, aunque de duración histórica variable (población indígena numerosa, socialmente marginada pero culturalmente autosuficiente; emergencia de la consciencia étnica; líder carismático, discurso "mítico-ideológico" de salvación colectiva; contexto internacional favorable), en una coyuntura de crisis abrupta y "distorsión cultural" iniciada en 1997, desencadenando con ello un movimiento de revitalización encabezado por un nuevo dirigente carismático, Evo Morales.

1997 fue el año en que el Gobierno reformista de la coalición MNR-MBLMRTKL, presidido por Gonzalo Sánchez de Lozada ("Goni") y Víctor Hugo Cárdenas, fue sucedido por el de Acción Democrática Nacionalista (ADN) del ex-dictador Hugo Bánzer, con el respaldo del MIR (de la Internacional Socialista) y los partidos populistas CONDEPA y UCS. Ese Gobierno de coalición, aunque formalmente una expresión más del régimen de "democracia pactada" entre partidos establecido en 1982, había sido responsable, bajo la consigna "Plan de todos", de iniciativas tales como las campañas de inscripción en el censo electoral; leyes como la de "Participación Popular", de fortalecimiento de la autonomía municipal, e INRA de reforma agraria, que reconocía las llamadas "tierras comunitarias de origen"; así como de una política que intentaba hacer efectivo el uso de las lenguas vernáculas en los 
centros de enseñanza y en la administración. En un esfuerzo adicional por mitigar los efectos socialmente más destructivos de la "Nueva Política Económica", impulsó una reforma electoral y constitucional para hacer de Bolivia una "República unitaria, multiétnica y pluricultural", de inspiración katarista. El resultado fue un nuevo sentido de participación ciudadana entre los étnica y socialmente marginados hasta entonces, animados por el discurso "multiculturalista" con el que el Gobierno justificaba sus acciones (Postero 2007: 6-7).

La llegada de Bánzer a la Presidencia significó el comienzo de una reacción contra ese impulso reformista: de vaciamiento de contenido de la "República multiétnica y pluricultural" mediante la paralización o ralentización de las reformas del "Plan de todos" (v. g., en la aplicación de la Ley INRA) (Yashar 2005: 218-223) y, por consiguiente, de vuelta al "neoliberalismo" sin matices de la "Nueva Política Económica" — no obstante el fin del ciclo de crecimiento- y alineamiento con los EE. UU. En agosto de 2001, Bánzer renunciaría por razones de salud, siendo sucedido por su vicepresidente, el ingeniero y economista, educado en los EE. UU., Jorge Quiroga.

La movilización contra el Gobierno de Bánzer y Quiroga surgió primero en El Chapare y tomó la forma de un recrudecimiento de las protestas, ya muy violentas, contra la política de persecución del cultivo de la hoja de coca, ahora bajo el más radical "Plan Dignidad" o de "Coca Cero", inspirado, alentado, asesorado y financiado por la Administración estadounidense de Bill Clinton. El Plan tenía como objetivo destruir 47.000 hectáreas de cultivo "y trasladar entre cinco y veinte mil familias, de las que vivían en El Chapare, hacia 'zonas de reasentamiento humano"' (Sivak 2008: 128). La multiplicación y extensión de los cocales a lo largo de una década —con la preceptiva emigración a los valles productores- había permitido paliar los efectos sociales y económicos del Decreto Supremo 21.060.

El aymara Morales, quien había ganado un escaño en el Congreso, y encabezaba las protestas ${ }^{14}$, no tardaría en justificar éstas apelando a las tradiciones culturales originarias a la vez que a la independencia nacional contra un nuevo colonialismo e imperialismo. La apelación al pasado prehispánico venía a favorecer la difusión de la consciencia étnica ya iniciada en la alta Bolivia y en las tierras bajas del Oriente, y promovida después por el discurso pro-diversidad indígena del Gobierno MNR-MBL-MRTKL. Desde 1994 los cocaleros ya eran mayoría en la katarista CSUTCB. La apelación al na-

\footnotetext{
${ }^{14}$ Entre otras acciones, "encabezó en 1998 una [...] marcha a pie que durante veintitrés días unió El Chapare con La Paz. La embajadora [de los EE. UU.] Donna Hrinak marcó la línea oficial al calificarla de 'narcomarcha' y el ministro de Gobierno, Guido Nayar, no aceptó debatir con Morales" (Sivak 2008: 128-129).
} 
cionalismo y al antiimperialismo hacía conectar la causa de Morales y sus seguidores a la de las clases humildes y medias de las ciudades — caldo de cultivo tradicional, junto con las minas, de la izquierda nacional—, más aún en una situación de nueva recesión económica; de modo que las movilizaciones en defensa de la hoja de coca pasaron pronto a convertirse en defensa del aprovechamiento boliviano de éste y los demás recursos del país frente a intereses extranjeros.

El punto de inflexión ascendente de esta conexión se alcanzó con la llamada "Guerra del Agua", en los primeros meses de 2000, que concitó un amplio movimiento de protesta, focalizado en Cochabamba, contra la explotación de este recurso por una compañía de capital europeo, Aguas del Tunari. El detonante fue un aumento de precios decidido por la compañía, que se consideró injustificado. "Trabajadores fabriles, estudiantes, desempleados, vecinos y campesinos se unieron en torno a la Coalición por la Defensa del Agua y de la Vida para protestar por el alza. Morales llevó cuatro mil cocaleros" (Sivak 2008: 130). Bánzer respondió decretando el estado de sitio, con el resultado de seis muertos y ciento setenta y cinco heridos. Pero el movimiento prevaleció y a Aguas del Tunari le fue rescindida la concesión de la explotación, que pasó a una cooperativa del país (Sivak ibid.). La victoria sería reconocida en el preámbulo de la actual Constitución como un hito en las "luchas" seculares del "pueblo boliviano".

Con ese precedente, en septiembre de ese mismo año Quispe inició una campaña en el Altiplano de corte de carreteras y marchas sobre La Paz. "Los insurgentes sostenían que no debían pagar por agua ni tierra y que no dejarían de plantar coca" (Sivak ibid:: 131). El objetivo último era político: asumir el Gobierno. "Además de disponer de una serie de nacionalizaciones y expropiaciones, [Quispe] reemplazaría el ministerio de Asuntos Campesinos por el de Asuntos Blancos y crearía una reserva de blancos en La Paz. [Tupaq] Katari era el modelo y ejemplo a seguir. 'Estamos en el tiempo del Pachakuti — dijo-: las piedras van a revelar cosas insospechadas y los ríos volverán a cantar" (en Sivak ibid.: 132). En otras palabras: un "juyzio final" aymara. No en la otra vida, sino en ésta.

En las elecciones de junio de 2002, el éxito del MAS y del MIP (fundado por Quispe en noviembre de 2000), obteniendo el 27\% de los votos, sólo podía sorprender a los partidos del régimen establecido en 1982, "los partidos sistémicos" (Sivak ibid:: 135-141), cada vez más alejados del pulso social y político del país. Sus máximos dirigentes se apresuraron entonces a cerrar el paso a la revolución potencial, nacionalista e indígena, que tenían enfrente. Unas semanas después de las elecciones, y con vistas a la elección por el Congreso del nuevo Presidente, los antaño enemigos Sánchez de Lozada, del MNR, y Paz Zamora, del MIR —aliado hasta la fecha del 
partido de Bánzer-, suscribieron el inesperado "Plan Bolivia de Responsabilidad Nacional" para un Gobierno de cinco años que se habría de dedicar principalmente a "combatir la extrema pobreza, a la generación de empleos y a la mejora del nivel de vida a través del desarrollo de la industria del gas natural" (El País, 27 de julio de 2002).

El acuerdo MNR-MIR sería apoyado por el resto de "los partidos sistémicos" y Sánchez de Lozada se convertiría en nuevo Presidente, esta vez sin pacto con el katarismo y contra la candidatura alternativa del MAS y el MIP en favor de Morales. Las opciones en liza eran claramente étnicas además de sociales: o se elegía al empresario criollo Sánchez de Lozada, educado como Quiroga en los EE. UU., o al sindicalista aymara Morales. Un diputado del MAS comentaría después que la elección del primero significaba que "no quedará otro camino que el de una revolución sangrienta, que es lo que queríamos evitar" (El País, 5 de agosto de 2002).

Fue por entonces cuando Morales empezó a abogar por la convocatoria de una "Asamblea Constituyente" que refundara Bolivia (Sivak 2008: 144) y a subir el tono contra el régimen de "democracia pactada" de 1982, con sus "pegas" y "repartijas" (favores políticos y reparto de cargos) y corrupción. En el nuevo Congreso presentó proyectos de ley para reducir los sueldos oficiales y recuperar el control nacional de los recursos naturales, aunque sin ningún éxito. Del nuevo Gobierno exigió la suspensión inmediata del Plan "Coca Cero"; a lo que Sánchez de Lozada - maniatado por la Administración de G. W. Bush, que relacionaba a Morales con el narcotráfico y el terrorismo internacional- se negó. En enero de 2003, Morales volvió a la estrategia de movilizaciones en la calle y en los campos, empezando con los cortes de carreteras (Sivak ibid: 133-137, 148-150).

Al contexto resultante de gran tensión social y política — saldado con una docena de muertos_ vinieron a añadírsele, pocas semanas después, los violentos enfrentamientos entre la policía y el ejército con ocasión del plan de austeridad prescrito por el Fondo Monetario Internacional: el llamado "Febrero Negro". Una petición de urgencia de ciento cincuenta millones de dólares al Tesoro de los EE. UU. fue acogida con reservas por parte de éste, y la nueva crisis "dejó treinta y tres muertos, ciento ochenta y nueve heridos y un futuro precario. Bolivia no podía resolver su crisis económica, Goni quedaba muy debilitado y Washington parecía poner ciertos límites a su alianza" (Sivak ibid.: 152).

La entrada de la populista NFR en el Gobierno (julio de 2003) no llegó a surtir efecto alguno. Pocas semanas después empezaba "La Guerra del Gas" o "de Octubre", otro hito en las luchas seculares del "pueblo boliviano" según el preámbulo de la actual Constitución. Sánchez de Lozada, que no había aprendido las lecciones de la "Guerra del Agua", se decidió a impulsar el 
"desarrollo de la industria del gas natural" como lo hubieran hecho Bánzer y Quiroga: dejándolo en manos privadas, a cambio del pago de unos derechos de poca cuantía para el Estado. El gas, en su mayor parte, se exportaría a México y los EE. UU. a través de Chile. Pero con Chile existía un sensible contencioso territorial desde el siglo xIx; y la idea de que el desarrollo de una industria sobre la base de un recurso natural equivalía a la explotación de este recurso en beneficio de empresas privadas hacía recordar los precedentes históricos de la producción de plata, estaño y caucho, en la que una parte muy pequeña del valor realizado había revertido al conjunto de la sociedad.

Estando el país en recesión económica, la indignación social fue explosiva y adoptó un claro tono nacionalista, mayor si cabe que en la "Guerra del Agua". A mediados de septiembre de 2003 se constituyó una "Coordinadora por la defensa y la recuperación del gas" que, junto con el MAS, movilizó a cincuenta mil personas en La Paz y veinte mil en Cochabamba. Mientras, la federación de las juntas de vecinos de El Alto y las comunidades aymaras del Altiplano, encabezadas por Quispe y recordando otra vez a Tupaq Katari, bloqueaban carreteras, incluido el acceso a La Paz y al aeropuerto (Sivak ibid.: 154-155). El Presidente reaccionó como lo había hecho Bánzer en 2000: enviando a la policía y al ejército contra los insurgentes. La represión, sin embargo — saldada con setenta y siete muertos y cuatrocientos heridos hasta el 16 de octubre-, no hizo sino propagar el movimiento: "los sectores medios se sumaron al conflicto con huelgas de hambre en iglesias y plazas". Ese día, "unas doscientas mil personas desbordaron la Plaza San Francisco [en La Paz] para exigir la renuncia de Sánchez de Lozada". Al día siguiente, finalmente, éste presentó la dimisión y huyó a los EE. UU. (ibid.: 155-160).

ANTAGONISMO SOCIAL, ÉTNICO Y TERRITORIAL

El resto ya lo conocemos en resumen. El presidente en funciones Carlos Mesa, fracasada su labor de mediación entre la insurgencia, de un lado, y "los partidos sistémicos", de otro, también renunciaría a la Presidencia menos de dos años después y el MAS vencería por mayoría absoluta en las elecciones anticipadas de diciembre de 2005. Morales no tendría necesidad de llegar a ningún acuerdo con Quispe. El cocalero era un dirigente sindical indiscutido desde finales de la década de 1980 y su "instrumento político", anclado en la CSUTCB desde 1994, supo atraer, con un discurso indianista a la vez que nacionalista — en todo caso, de ruptura con el régimen de "democracia pactada" de 1982, cuanto más con el anterior-, a la mayor parte del electorado del MIP así como a los sectores medios urbanos que 
se habían movilizado y organizado para la "Guerra del Agua" y la "Guerra del Gas". El acuerdo de Morales para la Vicepresidencia con el marxista e indigenista (y ex-guerrillero con Quispe) Álvaro García Linera terminó de apuntalar el ascendiente político del sindicalista a lo largo de todo el espectro de los sectores marginados del país. Todo él acabó apoyando su mensaje de salvación: ya no se trataba sólo de defender el cultivo de la hoja de coca contra el programa de erradicación de cultivos alentado por EE.UU., sino también de llevar a cabo una nueva política que defendiera la propiedad nacional de los recursos naturales de Bolivia. Para ello había que echar del poder a los partidos tradicionales y hacer frente al capitalismo transnacional.

En enero de 2006, en Tiahuanaco, Morales pudo así reformular el manifiesto katarista de 1973. Quería "unidad e igualdad" en el país y en el Continente, mientras anunciaba "el fin del neoliberalismo" y el comienzo de una "nueva era", de "un nuevo milenio", mediante una "Asamblea Constituyente" que refundara Bolivia. Explicó que había llegado "la hora de cambiar esa mala historia de saqueo de nuestros recursos naturales, de discriminación, de humillación, de odio, de desprecio [...]. Nos hemos convencido que concentrar el capital en pocas manos no es [...] la solución para los pobres del mundo". Si no fuera por el eco en ese discurso de la cosmología indígena - la que divide a la población en dos mitades sociales y políticas y las hace alternar cíclicamente en las posiciones de preeminencia y subordinación-, lo proclamado podría pasar por el anuncio de una versión actualizada de la Revolución Nacional de 1952 y el régimen del MNR, como ha apuntado el analista Fernando Molina (2009). Como entonces, se hacía asumir al Estado nacional un papel de medio de reproducción del conjunto de la sociedad, incluida la población indígena.

La oposición representada por "los partidos sistémicos", aunque desplazada de la mayoría en el Congreso, venció, no obstante, con claridad en los departamentos del este y sur del país, precisamente aquellos donde están los yacimientos de petróleo y gas natural y donde se concentra la población de ascendencia no originaria. No tardaría por eso en enarbolar la bandera de la descentralización y, en seguida, de la autonomía de los departamentos respecto del nuevo Estado nacionalizador y redistribuidor. En consecuencia, el antagonismo político visible en el nuevo Congreso y en la Asamblea Constituyente (elegida en julio de 2006) tendría ahora también un carácter territorial. Al contrario de lo apuntado por Raúl Madrid, es difícil entender este antagonismo —-muy violento después de 2005- si no se hubiera producido en el país una polarización étnica real, además de social, que lo hubiera facilitado, interrumpiendo así, en tal momento histórico iniciado en 1997, la ambigüedad de ese sentido de pertenencia en la población. 
Paradójicamente, frente a las "naciones y pueblos indígena-originariocampesinos" del discurso de Morales y contemplados en la nueva Constitución (mucho más frente a la "nación aymara" de Quispe), ese movimiento opositor social y también étnico — concentrado en la llamada "Media Luna", por la forma geográfica del conjunto de los departamentos que domina (Pando, Beni, Santa Cruz y Tarija) — tendía y tiende a reivindicar el Estado unitario constitucional, sobre la base, por tanto, del otro concepto de nación, el voluntarista y participativo de 1826, del que la población originaria fuera excluida.

Lo que significa otra diferencia con España. Aquí es el autonomismo, más aún el soberanismo, el que esgrime la nación genealógica frente a la territorial del régimen constitucional.

\section{BIBLIOGRAFÍA CITADA}

Acosta, J. de. 2008 [1590]. Historia natural y moral de las Indias. Edición de F. del PinoDíaz. Madrid: CSIC.

Albó, X. 1990a. "El campo: nuevos ferrocarriles y viejas masacres", en X. Albó y J. M. Barnadas, La cara india y campesina de nuestra historia: 151-164. La Paz: UNITAS/ CIPCA, $3^{a}$ edición.

Albó, X. 1990b. "Los años 80", en X. Albó y J. M. Barnadas, La cara india y campesina de nuestra historia: 265-296. La Paz: UNITAS/CIPCA, $3^{\text {a }}$ edición.

Albó, X. 2007. "Bolivia: avances y tropezones hacia un nuevo país plurinacional e intercultural", en S. Martí i Puig (ed.), Pueblos indígenas y política en América Latina: El reconocimiento de sus derechos y el impacto de sus demandas a inicios del siglo XXI: 335-359. Barcelona: Fundació CIDOB.

Albó, X. y J. M. Barnadas. 1990. La cara india y campesina de nuestra historia. La Paz: UNITAS/CIPCA, $3^{\text {a }}$ edición.

Alcántara Sáez, M. y P. Marenghi. 2007. "Los partidos étnicos de América del Sur: algunos factores que explican su rendimiento electoral", en S. Martí i Puig (ed.), Pueblos indígenas y política en América Latina: El reconocimiento de sus derechos y el impacto de sus demandas a inicios del siglo XXI: 57-101. Barcelona: Fundació CIDOB.

Álvarez, B. 1998 [1588]. De las costumbres y conversión de los indios del Perú. Edición de M. C. Martín Rubio, J. J. R. Villarías-Robles y F. del Pino-Díaz. Madrid: Polifemo.

Anderson, B. 1991. Imagined Communities: Reflections on the Origin and Spread of Nationalism. Revised Edition. Londres y Nueva York: Verso.

Asamblea Constituyente de Bolivia. 2008. Nueva Constitución Política del Estado. La Paz: Congreso Nacional. (Disponible en: http://www.ernestojustiniano.org/index_files/ nueva_cpe_abi.pdf.)

Barnadas, J. M. 1990a. "Desde 1952: promesas y traiciones", en X. Albó y J. M. Barnadas, La cara india y campesina de nuestra historia: 207-211. La Paz: UNITAS/CIPCA, $3^{\text {a }}$ edición.

Barnadas, J. M. 1990b. "Divagaciones algo distanciadas", en X. Albó y J. M. Barnadas, La cara india y campesina de nuestra historia: 297-309. La Paz: UNITAS/CIPCA, $3^{\underline{a}}$ edición. 
Barnadas, J. M. 2006. "¿Cómo se ha llegado en Bolivia a la victoria del MAS? Reflexiones sobre la crisis de un Estado pluricultural y multiétnico". Conferencia pronunciada en el Departamento de Antropología de España y América del CSIC, Madrid, 16 de febrero de 2006.

Barnadas, J. M. 2009. "L'església i les nacions sense estat (nota sobre doctrina pontifícia i pràctica vaticana)", en E. Claros y C. Rosso (eds.), 40 años de compromiso con Bolivia (1969-2009). Homenaje a Hans van den Berg: II, 358-374. La Paz: Universidad Católica Boliviana.

Barnadas, J. M. et alii (eds.). 2002. Diccionario Histórico de Bolivia, en 2 Vols. Sucre: Grupo de Estudios Históricos.

Barreda, M. 2006. "De la democracia pactada al proceso constituyente: ¿hacia un nuevo modelo de gobernabilidad en Bolivia?, en P. Domingo (ed.), Bolivia: fin de un ciclo y nuevas perspectivas políticas (1993-2003): 65-91. Barcelona: Bellaterra.

Braudel, F. 1958. "Historia y ciencias sociales: la larga duración". Cuadernos americanos CI (6): 73-110.

Bertonio, L. 1984 [1612]. Vocabvlario de la lengva aymara. Cochabamba: CERES.

Cárdenas, V. H. 2002. "Fausto Reinaga", en J. M. Barnadas et alii (eds.), Diccionario Histórico de Bolivia, Vol. II: 697. Sucre: Grupo de Estudios Históricos.

Cieza de León, P. de. 1984 [1553]. La crónica del Perú. Edición de M. Ballesteros Gaibrois. Madrid: Historia 16.

Cieza de León, P. de. 1985 [ca. 1550]. El señorío de los incas. Edición de M. Ballesteros Gaibrois. Madrid: Historia 16.

Condarco Morales, R. 1965. Zárate, el "temible" willka: historia de la rebelión indígena de 1899. La Paz: Talleres Gráficos Bolivianos.

Daniel, J. 1995. Viaje al fondo de la nación. Traducción de O. L. Molina S. Santiago de Chile: Andrés Bello.

De Mesa, J. et alii. 1998. Historia de Bolivia, Segunda Edición corregida y actualizada. La Paz: Gisbert.

Ediciones Akal. 2003. El estado del mundo, 2004: Anuario económico geopolítico mundial. Traducción de R. Mecha López. Madrid: Akal.

Elorza, A. 2005. "La nación española". El País (Madrid), 21 de noviembre de 2005.

Fernández Juárez, G. 2004. Yatiris y ch'amakanis del altiplano aymara: sueños, testimonios y prácticas ceremoniales. Quito: Abya Yala.

García Linera, A. 2008 [2005]. "Marxismo, nacionalismo e indianismo en Bolivia. La 'Nueva izquierda' del presidente Morales". Le Monde diplomatique en español XII (150), abril 2008: 25.

Gellner, E. 1997. Nationalism. Londres: Weidenfeld \& Nicolson.

Goldman, N. (dtora.) 1998. Revolución, república, confederación (1806-1852). Buenos Aires: Sudamericana.

Guzmán, A. 1990. Historia de Bolivia. Cochabamba: Los Amigos del Libro. 7a edición.

Herder, J. G. 1959 [1784-1791]. Ideas para una filosofía de la historia de la humanidad. Trad. de J. Rovira Armengol. Buenos Aires: Losada.

Hobbes, Th. 1968 [1651]. Leviathan. Edición de C. B. Macpherson. Harmondsworth, R. U.: Penguin.

Hobsbawm, E. J. 1990. Nations and Nationalism since 1780: Programme, Myth, Reality. Cambridge: Cambridge University Press.

Hobsbawm, E. J. y T. Ranger (eds.). 1983. The Invention of Tradition. Cambridge: Cambridge University Press. 
Iglesias Turrión, P. 2007. "Las clases peligrosas. La interfaz boliviana en la resistencia global al capitalismo", en J. Espasandín López y P. Iglesias Turrión (coords.), Bolivia en movimiento: Acción colectiva y poder político: 259-284. Barcelona: El Viejo Topo.

Irurozqui, M. 2000. "A bala, piedra y palo". La construcción de la ciudadanía política en Bolivia, 1826-1952. Sevilla: Diputación de Sevilla.

Irurozqui, M. 2006. "La transgresión electoral. Propuesta conceptual sobre su valor en la materialización del ciudadano. Bolivia (1825-1952)", en P. Domingo (ed.), Bolivia: fin de un ciclo y nuevas perspectivas políticas (1993-2003): 39-64. Barcelona: Bellaterra.

Klein, H. S. 1985. Historia general de Bolivia. Traducción de J. M. Barnadas. La Paz: Juventud, $2^{\underline{a}}$ edición.

Kolata, A. L. 1993. The Tiwanaku: Portrait of an Andean Civilization. Cambridge, EE. UU.: Blackwell.

Lara, J. 1997. Diccionario qheshwa-castellano, castellano-qheshwa. La Paz y Cochabamba: Los Amigos del Libro, $4^{\text {a }}$ edición.

Layme Pairumani, F. et alii. 1992. Diccionario Castellano-Aimara. La Paz: Presencia.

Lazarte, J. 2006. "¿Son necesarios aún los partidos políticos? La alternativa de las Agrupaciones Ciudadanas y de Pueblos Indígenas", en P. Domingo (ed.), Bolivia: fin de un ciclo y nuevas perspectivas políticas (1993-2003): 93-117. Barcelona: Bellaterra.

Lévi-Strauss, C. 1968 [1949]. "Historia y etnología", en Antropología estructural, de Claude Lévi-Strauss: 1-26. Traducción de E. Verón. Buenos Aires: EUDEBA.

Locke, J. 1948 [1690]. An Essay Concerning The True Original, Extent and End of Civil Government, en J. Locke, The Second Treatise of Civil Government and A Letter Concerning Toleration: 3-120. Edición de J. W. Gough. Oxford: Basil Blackwell.

López Calera, N. 1995. El nacionalismo, ¿culpable o inocente? Madrid: Tecnos.

Lyotard, J-F. 1986 [1979]. La condición posmoderna. Madrid: Cátedra.

Madrid, R. L. 2008. "The Rise of Ethnopopulism in Latin America". World Politics 60 (3): 475-508.

Martí i Puig, S. 2007. "Emergencia de lo indígena en la arena política: ¿un efecto no deseado de la gobernanza?”, en S. Martí i Puig (ed.), Pueblos indígenas y politica en América Latina: El reconocimiento de sus derechos y el impacto de sus demandas a inicios del siglo XXI: 127-147. Barcelona: Fundació CIDOB.

Marx, K. 1945 [1852]. Le 18-Brumaire de Louis Bonaparte. París: Éditions Sociales, $2^{\mathrm{a}}$ edición.

Marx, K. 1971 [1852]. El dieciocho de brumario de Luis Bonaparte. Barcelona: Ariel.

Marx, K. 1972 [1852]. "Der achtzehnte Brumaire des Louis Bonaparte", en Karl Marx, Friedrich Engels, Werke 8: 113-207. Berlín: Dietz.

Molina, F. 2009. "El MAS, partido de Estado". Infolatam 7 de diciembre de 2009 (disponible en http://www.infolatam.com)

Parlament de Catalunya. 2005. Dossier per a la sessió núm. 66.3. Convocada per al dia 30 de setembre de 2005. Proposta de Proposició de llei orgànica per la qual s'estableix l'Estatut d'autonomia de Catalunya i es deroga la Llei orgànica 4/1979, del 18 de desembre, de l'Estatut d'autonomia de Catalunya (disponible en: http://www.iceta.org/ estatu29.pdf).

Pérez Garzón, J. S. 2009. "El nacionalismo español: los resortes de una hegemonía política y cultural", en M. Janué i Miret (ed.), Pensar hisòricament: Ética, ensenyament $i$ usos de la historia: 123-145. Valencia: Universitat de València.

Ponce Sanginés, C. 1981. Tiwanaku: Espacio, tiempo y cultura. Cochabamba: Los Amigos del Libro. $4^{\underline{a}}$ edición. 
Postero, N. G. 2007. Now We Are Citizens: Indigenous Politics in Postmulticultural Bolivia. Stanford, California: Stanford University Press.

Rivera Cusicanqui, S. 1986. "Oprimidos pero no vencidos". Luchas del campesinado aymara y quechwa de Bolivia, 1900-1980. Ginebra: Instituto de Investigaciones de las Naciones Unidas Para el Desarrollo Social (UNRISD).

Rivera Cusicanqui, S. 2007. "Que el pasado sea futuro depende de lo que hagamos en el presente: enseñanzas de la insurgencia étnica en Bolivia", en J. Espasandín López y P. Iglesias Turrión (coords.), Bolivia en movimiento: Acción colectiva y poder político: 101-128. Barcelona: El Viejo Topo.

Rodríguez Mir, J. 2008. "Complejidad, diversidad y heterogeneidad social. Bolivia y sus implicaciones multiculturales desde una antropológica”. Revista de Antropología Experimental 8: 341-349.

Salomon, F. 1982a. "Andean Ethnology in the 1970s: A Retrospective". Latin American Research Review 17 (2): 75-128.

Salomon, F. 1982b. "The Andean Contrast". Journal of International Affairs 36 (1): 5571.

Savater. F. 1996. El mito nacionalista. Madrid: Alianza.

Sivak, M. 2008. Jefazo: retrato íntimo de Evo Morales. Buenos Aires: Sudamericana.

Tovar, A. 1984. Catálogo de las lenguas de América del Sur. Nueva edición refundida. Madrid: Gredos.

Van Cott, D. L. 2003. "Cambio institucional y partidos étnicos en Suramérica". Análisis Político 48 (enero-abril): 26-51.

Villarías-Robles, J. J. R. 1997. "La vuelta del Inca Rey. Textos, tradición oral y acción política en el milenarismo andino”, en L. Díaz Viana y M. Fernández Montes (eds.), Entre la palabra y el texto. Problemas en la interpretación de fuentes orales y escritas: 103-142. Madrid y Oiartzun: CSIC-Sendoa.

Wallace, A. 1956. "Revitalization Movements". American Anthropologist 58 (2): 264-281.

Yashar, D. J. 2005. Contesting Citizenship in Latin America: The Rise of Indigenous Movements and the Postliberal Challenge. Cambridge: Cambridge University Press.

Fecha de recepción: 30 de junio de 2009.

Fecha de aceptación: 2 de diciembre de 2009.

RDTP, vol. LXV, n. ${ }^{\circ}$ 1, pp. 215-254, enero-junio 2010, ISSN: 0034-7981, eISSN: 1988-8457, doi: 10.3989/rdtp.2010.003 